DOI: http://www.doi.org/10.25130/tjaes.17.55.1.1

أثر الإفصاح البيئي على تقنيات الإنتاج الأنظف/دراسة استطلاعية

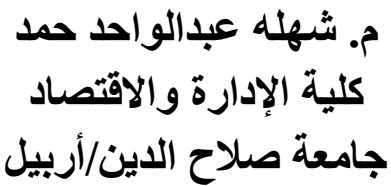

Shahla.hamad1971@gmail.com

المستخلص: - ان

يتناول الدراسة أثز الافصاح البيئي على تقنيات الانتاج الأنظف، ومن اجل اثبات فرضية

الدراسة تم نشر رابط الخاص باستمارة الاستبيان على مواقع التواصل الاجتماعي وتمت الاجلى الاجابة

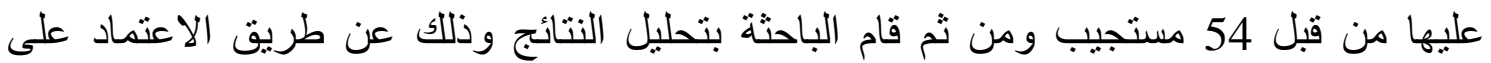
البرنامج الاحصائي SPSS، وتوصلت الدراسة الى عدة استنتاجات من أهمها ان للافصساح البيئي أثر على اعتمادية الانتاج الأنظف، وفي نهاية الدراسة تم وضئ وضع مجموعة من التوصيات من اهمها

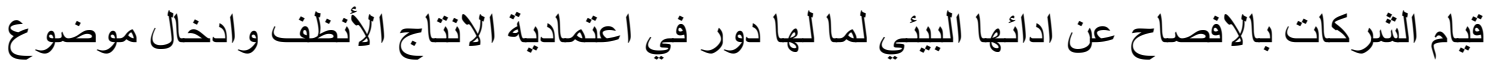
المحاسبة في المناهج الدر اسية للجامعات و المعاهد.

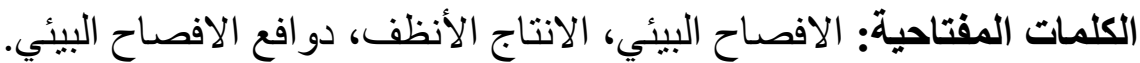

\title{
The impact of Environmental Disclosure on Cleaner Production Techniques/an Exploratory Study
}

\author{
Lecturer: Shahla Abdulwahid Hamad \\ College of Administration and Economics \\ Salahaddin University/Erbil
}

\begin{abstract}
:
The study deals with the extent of the impact of environmental disclosure on cleaner production techniques, and in order to prove the hypothesis of the study, a link to the questionnaire was published on social networking sites and it was answered by 54 respondents, and then the researcher analyzed the results by relying on the SPSS statistical program, and the study found To a series of results, the most important of which is that environmental disclosure has an impact on the reliability of cleaner production, and at the end of the study a set of recommendations were developed, the most important of which is that companies disclose their environmental performance because they have a role in the reliability of cleaner production and the introduction of the issue of accounting in the curricula of universities and institutes.
\end{abstract}

Keywords: environmental disclosure, cleaner production, motives for environmental disclosure.

المقدمة

ان موضوع البيئة اصبح أحد المواضيع المهمة التي حظيت باهتمام كبير في السنوات الأخيرة في مختلف المجتمعات والدول ويعود السبب في ذللك إلى تزايد الدور الكبير الذي تؤديه البيئة في حياة الإنسان، حيث يلاحظ أن عمليتي الانتاج والتنمية كان لهما دور مباثر في تلوث البيئة وذلك بسبب عدم أخذ اعتبار ات البيئة بنظر الاعتبار عند التخطيط للعمليات الانتاجية، وتقوم 
الثركات باصلاح ما احدثه من الضرر في البيئة التي تعمل في محبطه والافصاح عن مساهماتها

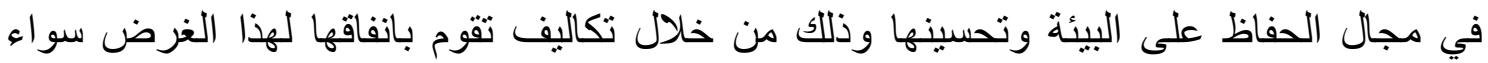
اكانت تقوم بذلك بشكل اجباري او اختياري.

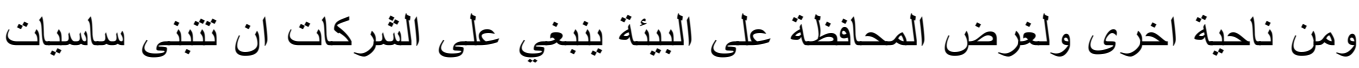
تسهم في تحقيق ذللك، ومن بين هذه السياسات سياسة الانتاج الأنظف و التي تساهم في تخفيض التئل الاثار السلبية تجاه البيئة بما فيها استهلاك اقل قدر للطاقة والحد من اندان انبعاث الغاز ات و الملوثات و واستخدام معايير تؤدي إلى الحد من تدفق النفايات وتجعلها قابلة للتدوير و التحول بالثركات دنات إلى التى تحقيق الكفاءة البيئية وهي بذلك تهدف إلى الحفاظ على الموارد الأولية و التخلص من المواد السامة وتقليل تدفقها و الحد من خطورتها. و عليه تحاول الباحثة هنا بيان مدى دور الافصاح التى تقوم بها الثركات عن مساهماتها

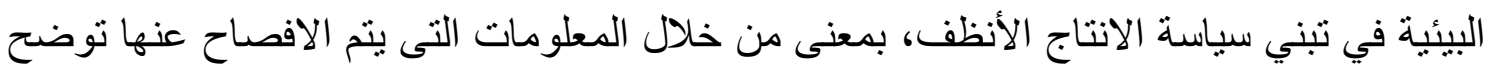

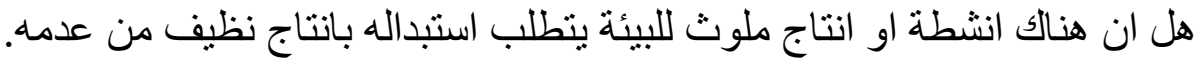
مشكلة الدراسة: ان الثركات بشكل عام تقع على عاتقها مسؤولية مساهمتها البيئية سواء اكانت

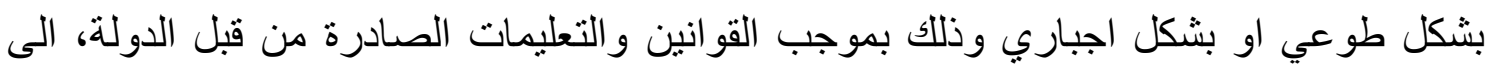

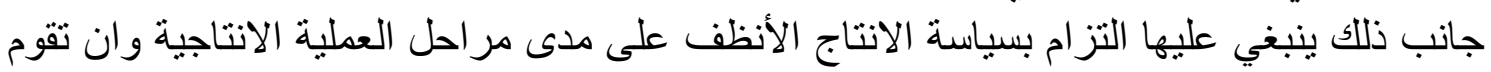
بهذا الدور بشكل مرضي و عليه يمكن طرح اشكالية الدراسة على النحو التالي: 1. هل الافصاح عن الأنشطة البيئية الخاصة بطبيعة العملية الانتاجية له نأثير في استبدالها بالإنتاج الأنظف؟ r. هل الافصاح عن الأنشطة البيئية الخاصة بالتغيرات في المواد الاولية له تأثثر في استبدالها بالإنتاج الأنظف؟

؟. هل الافصاح عن الأنشطة البيئية الخاصة بتطوير المعدات له تأثير في استبدالها بالإنتاج الأنظف؟ ع. هل الافصاح عن الأنشطة البيئية الخاصة بالتغير في تصميم المنتج له تأثثر في استبدالها بالإنتاج الأنظف. ๑. هل الافصاح عن الأنشطة البيئية الخاصة بإدارة النفايات و المخلفات له تأثثر في استبدالها بالإنتاج الأنظف؟ الهمية الدراسة: تنبع اهمية الدراسة في انه تسلط الضوء على الافصاح البيئي ولما لها من دور في

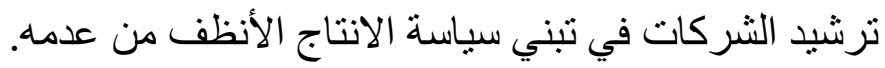

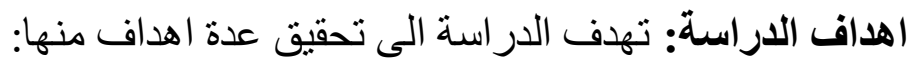

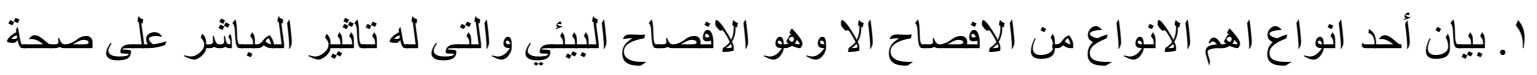

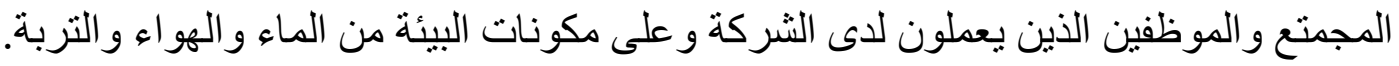
r. عرض اهم انواع سياسات التى تتبناها بعض الثركات الا وهو سياسة الانتاج الأنظف. لأفئ.

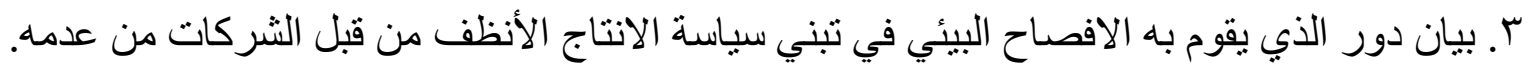

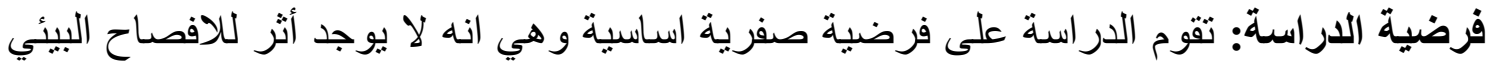

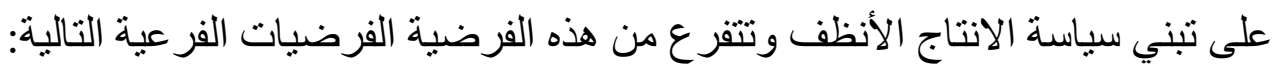

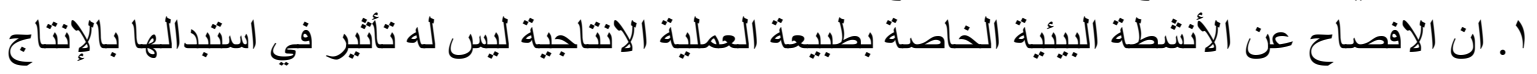
الأنظف. 
r. ان الافصاح عن الأنثطة البيئية الخاصة بالتغيرات في المواد الاولية ليس له تأثثير في استبدالها

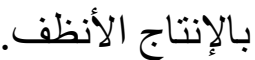
r. ان الافصاح عن الأنشطة البيئية الخاصة بتطوير المعدات واستبدالها ليس له تأثير في استبدالها

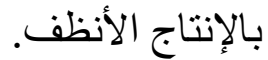
ع. ان الافصاح عن الأنشطة البيئية الخاصة بالتغير في تصميم المنتج ليس له تأثثر في استبدالها بالإنتاج الأنظف. الإحن. ه. ان الافصاح عن الأنشطة البيئية الخاصة بإدارة النفايات والهخلفات ليس له تأثثر في استبدالها بالإنتاج الأنظف. الإحن.

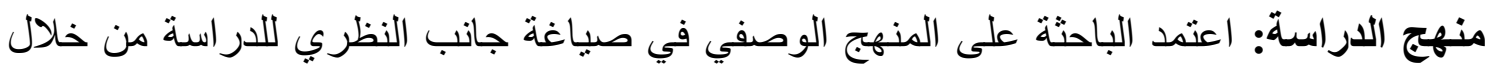
الرجوع إلى الكتب والدوريات العلمية وفي نفس الوقت الدت تم اعتماد المنهج الاستنباطي التحليلي في الجانب التطبيقي منه من خلال تنظيم استمارة الاستبيان.

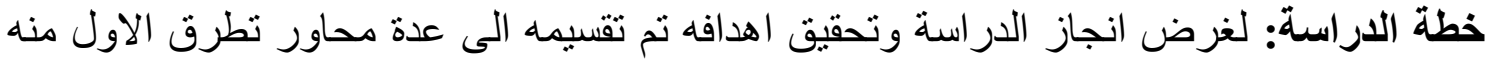

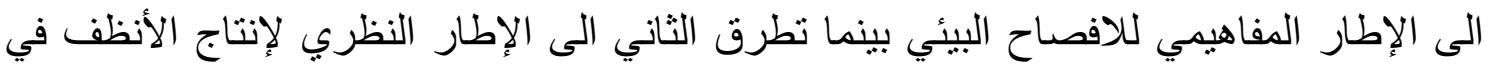

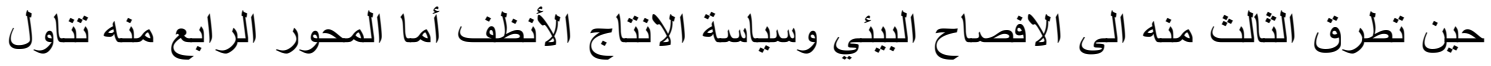

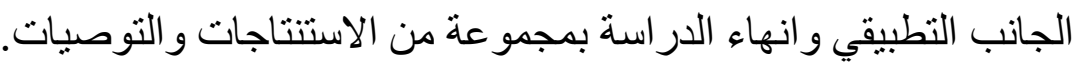

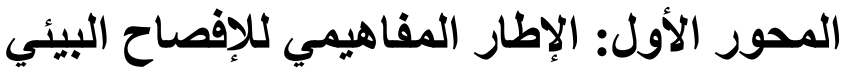

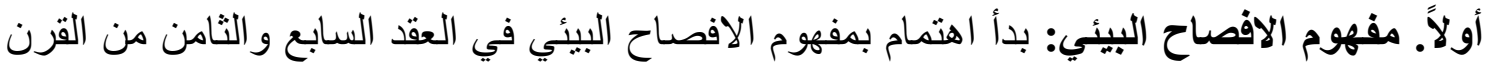

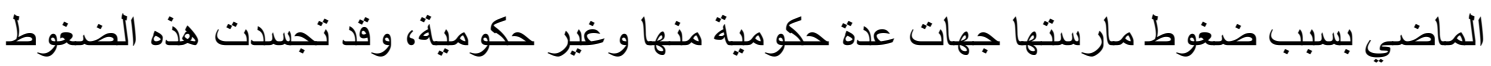

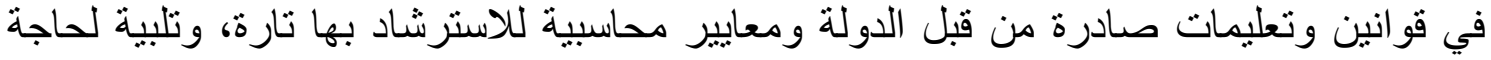

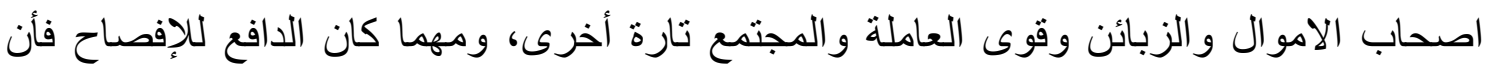

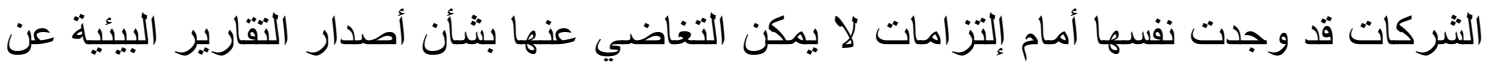

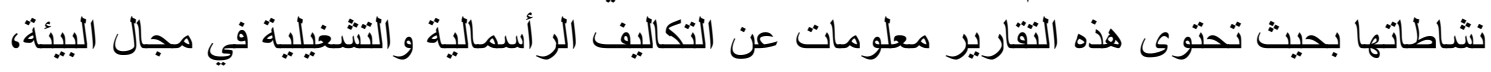

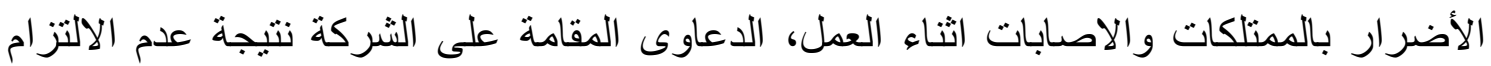

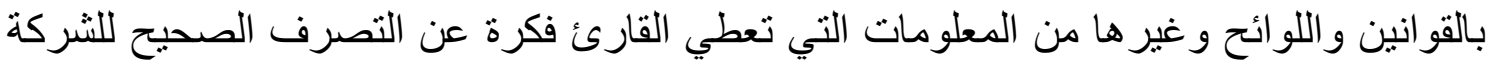

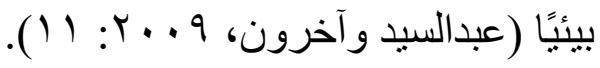

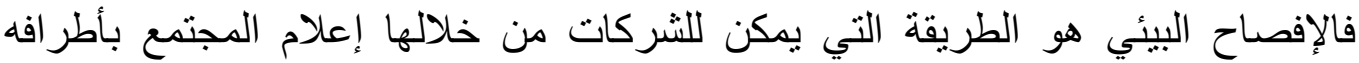

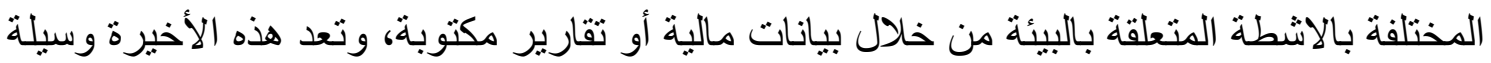

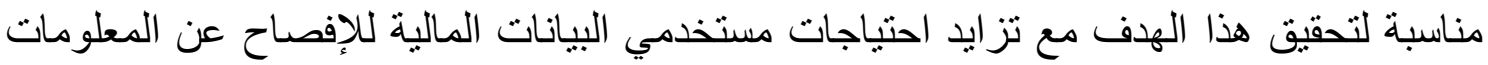

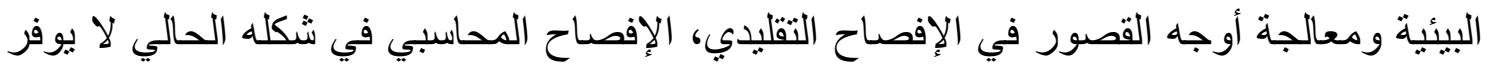

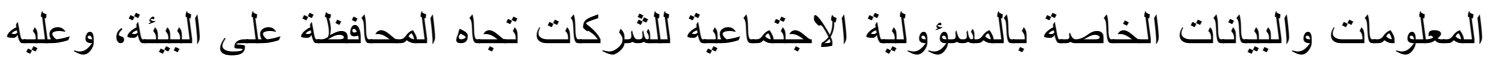

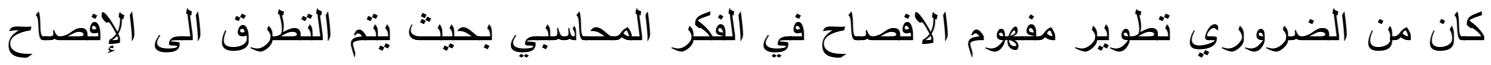

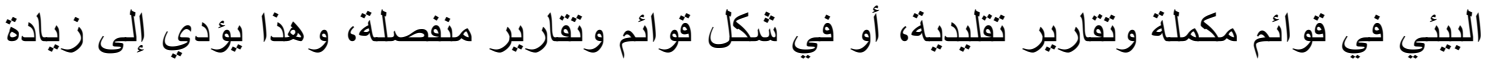

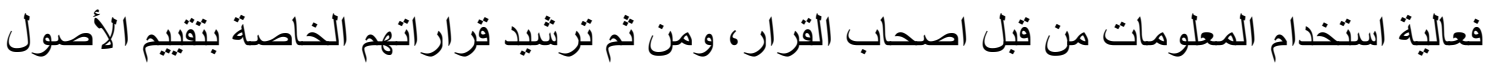
المالية والأداء الاقتصادي (Sief, 2014:363). 
وعليه بمكن تعريف الافصاح البيئي بأنه الأسلوب أو الطريقة التي تستطيع بواسطته الثركات إعلام المجتمع بأطر افه المختلفة بنشاطاتها ذات المضمون البيئي، وتعد القوائم المالية أو التقارير بائه

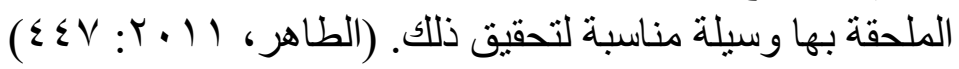

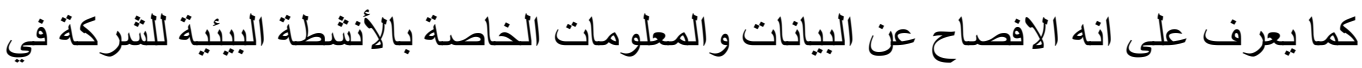

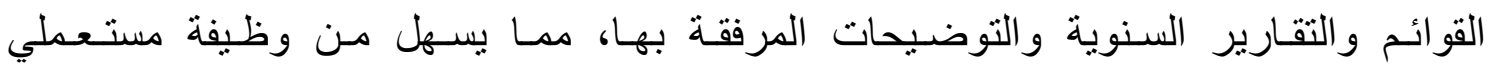

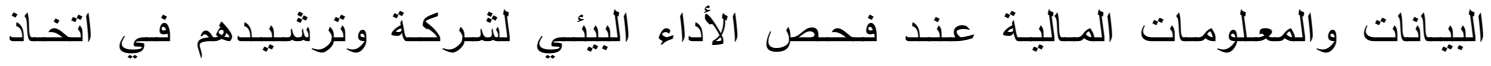

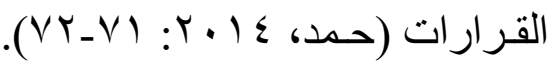

ويعرف الباحثة الافصاح البيئي بأنه عرض البان المعلومات البيئية والخاصة بالانشطة الانتاجية التى تمارسها الشركة وذلك في القوائم و التقارير المالية وهذا بساعد مستخدمي تللك البيانات و المعلومات البيئية على تقييم مستوى اداء البيئي للشركة.

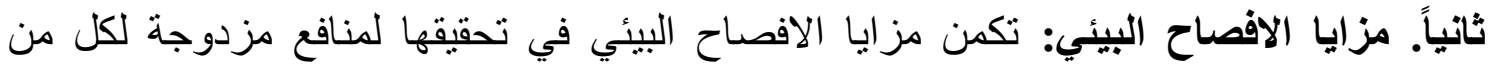

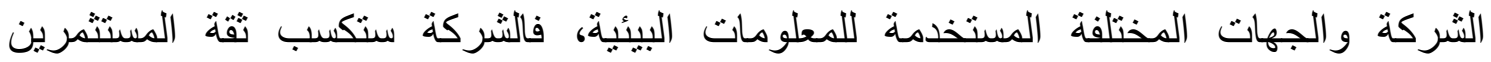

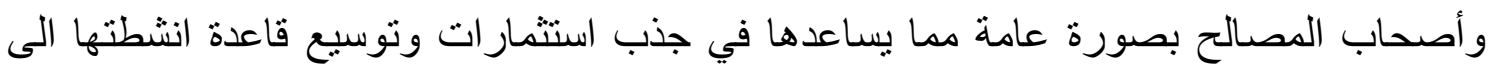
جانب وفائها بمسؤولياتها البيئية والاخلاقية وفي نفس الوقت فاهية دهاع الجهات المستخدمة للمعلومات

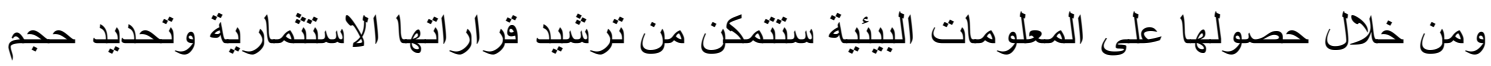
المخاطر البيئية و المشاكل القانونية التي يمكن نواجهرا تللك الثركات من عدمها في ضو ضوء مساهمة

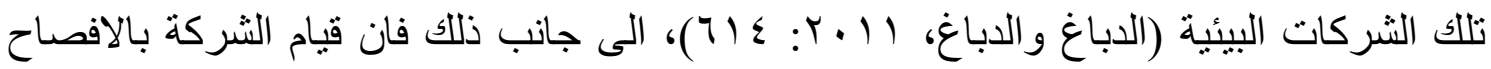

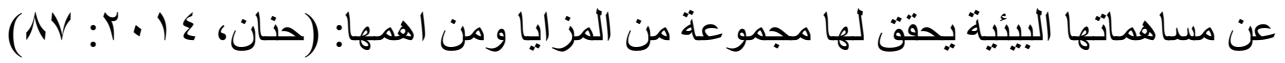

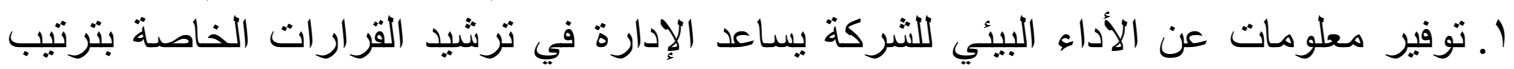

العمليات التصنيعية بقصد الانسجام مع التعليمات البيئية.

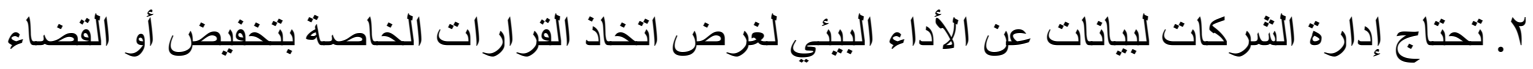

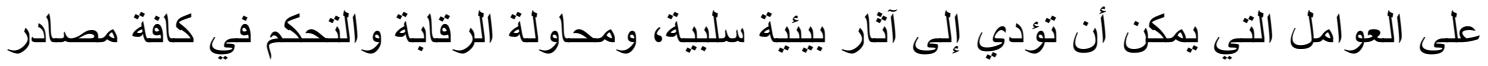

ب. الإفصاح المحاسبي عن التأثيرات البيئية يساعد الثركات على اتخاذ القرارات المتعلقة بأنشطة الإخفاق البيئي، مثل: تكاليف معالجة النفايات الضارة بيئيًا وغرامات مخالفة القوانين والأنظمة

ـ. يمكن الثركة من الحصول على أعلى معدلات للعائد على حق الملكية في حالة الإفصاح عن التأثير ات البيئية. ه. تزويد معلومات عن الأداء البيئي بحيث تساعد القائمين على الثركة في تصنيع منتجات صديقة

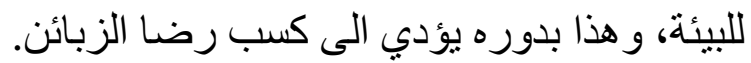

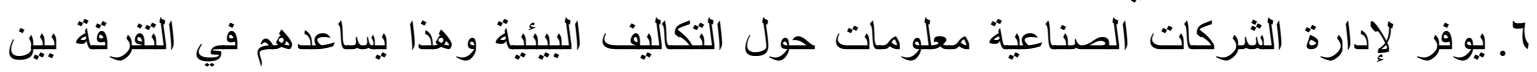

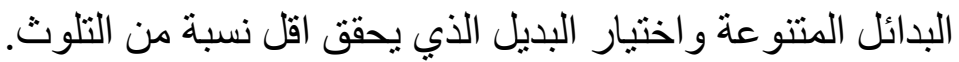

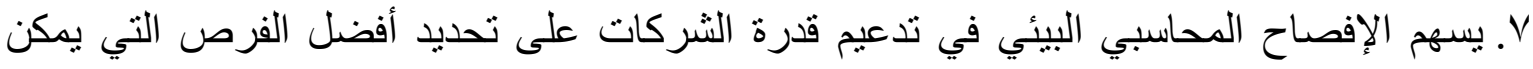
بواسطتها تقليل من تكاليف التشغيل البيئية الى جانب تقليل من استخدام الموارد و الطاقات.

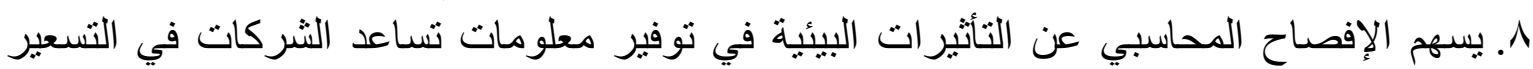
المنتجات وذلك بأخذ التكلفة البيئية في الاعتبار . 


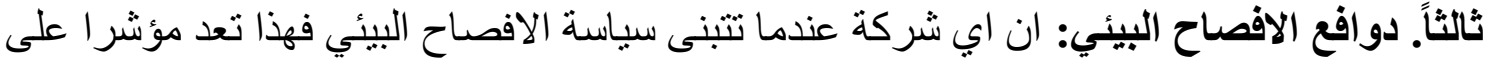

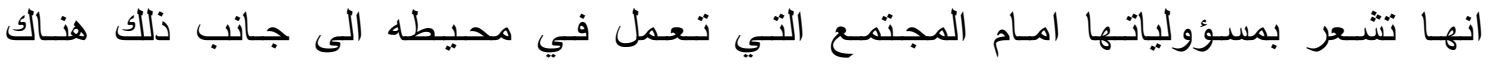
مجموعة من الدوافع تجعل الثركات ان تنبنى سياسـة الافصـاح البيئي ومـن الهـهـا:

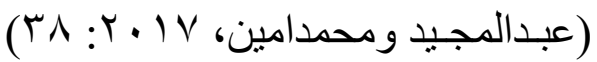

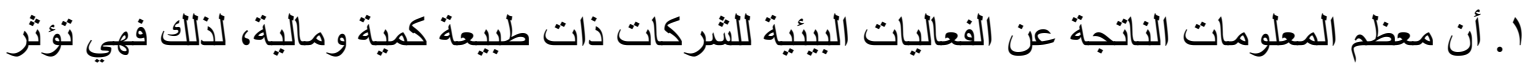

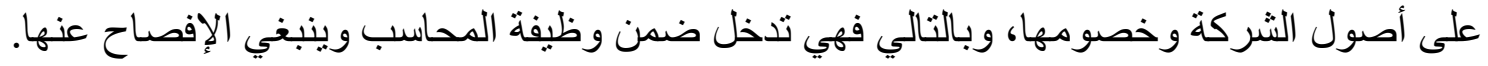

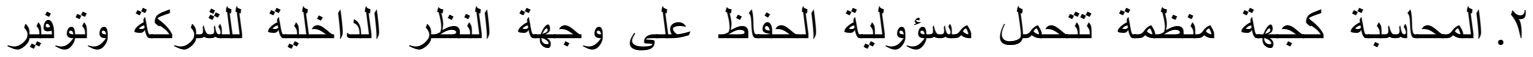

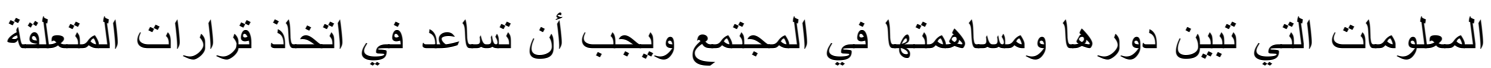

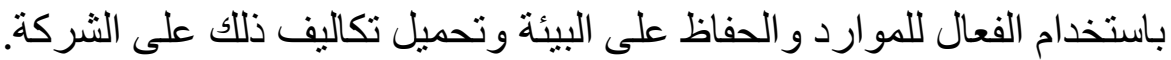

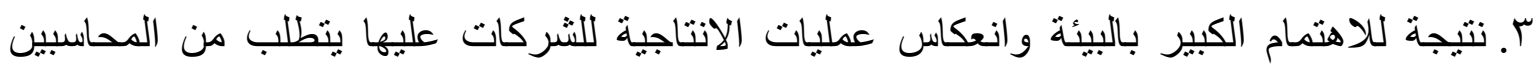
توفير المعلومات التي تساعد إدارة الثركات في تحديد الآثار السلبية لتلائك العمليات على البياتئية وكيفية معالجتها. ع. مطالبة الجهات والهيئات العلمية الثركات بضرورة الإفصاح عن المعلومات المتعلقة بالأنشطة البيئية للوفاء بالاحتياجات الجديدة للمجتمع وتحقيق التئية الهدافها.

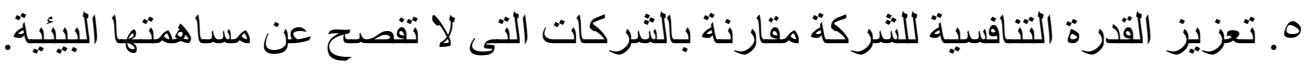

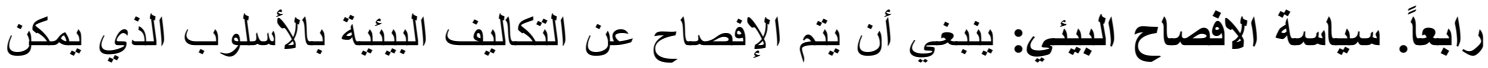

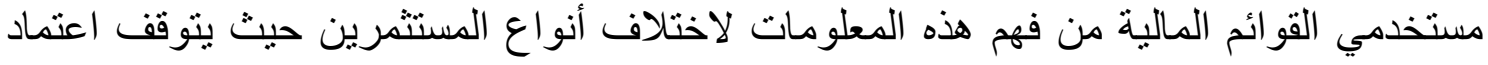

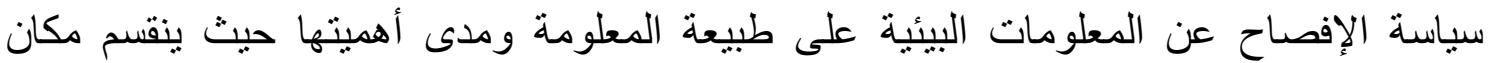

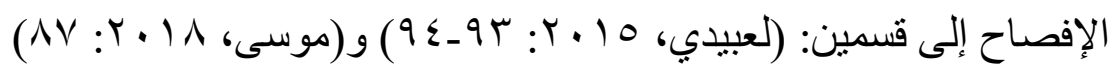

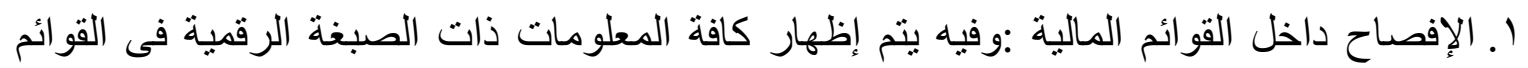

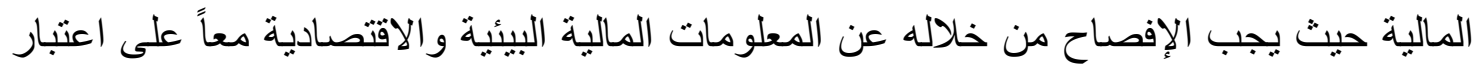
انهما متكاملان ويشكلا سويا التعبير الكامل و الثنامل عن أداء الثرات الثركة.

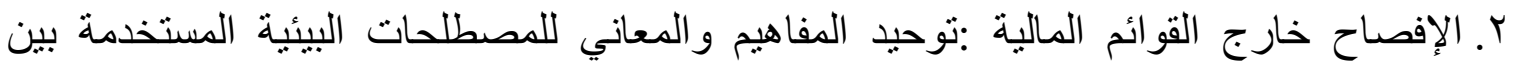

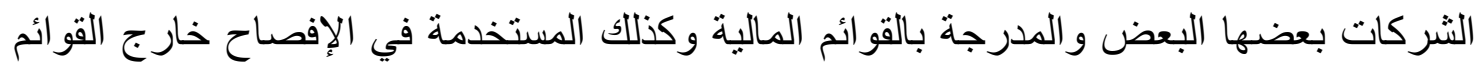

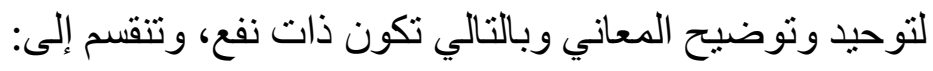

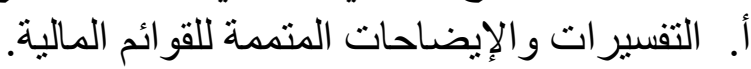
ب. البيانات الإضافية الدرجة بين الأقو اس.

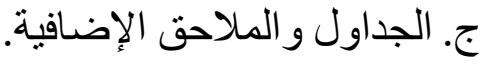

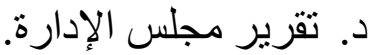

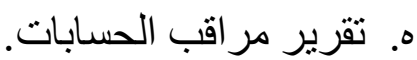

\section{المحور الثاني: الإطار النظري لإنتاج الأنظف}

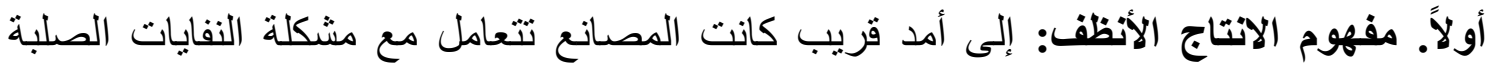

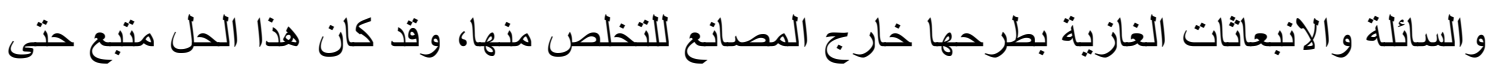

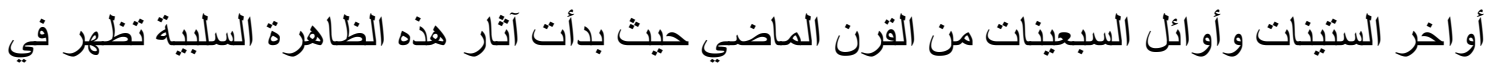

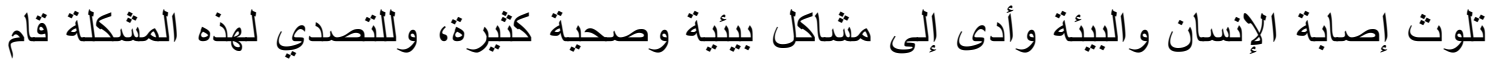

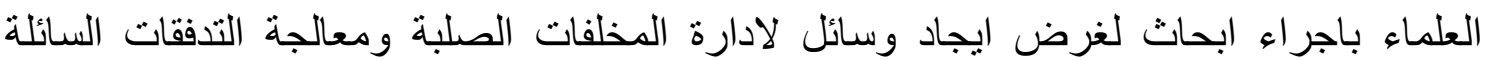


و التحكم في الانبعاثات الغازية وتم اكتشاف تقنيات الوقاية من التلوث وسمي لاحقا بتقنيات الانتاج

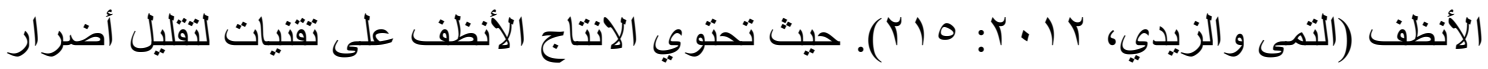

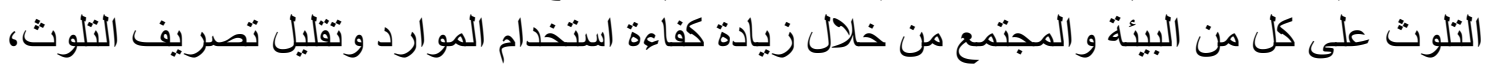

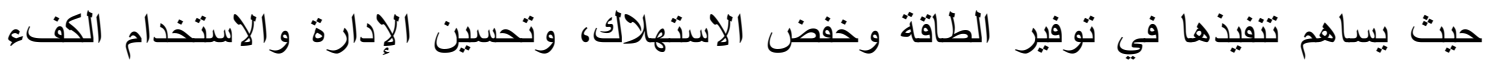
للموارد ويحمي البيئة و المستهلك والعامل مع تحسين الكفاءة الصناعية و الربحية و القدرة التنافسية.

(Dattane and et al., 2013: 701) وتم تعريف الإنتاج الأنظف (CP) من ضمن برنامج الامم المتحدة للبيئة على أنه "التطبيق

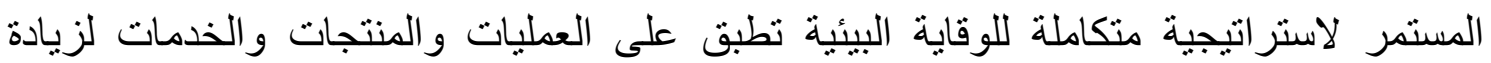
الكفاءة الكلية و الحد من المخاطر التى يتعرض لها الإنسان والبيئة (Doorasamy, 2015: 236).

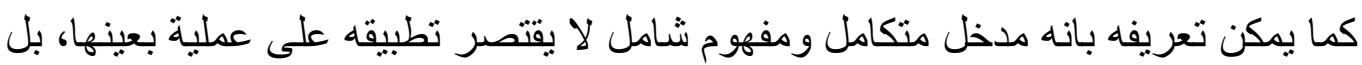
يشمل النظام ككل انطلاقاً من المدخلات فالعمليات وصولاًا إلى المخرجات، ويتطلب تطبيقه تو افر المعرفة والأفكار المبتكرة والتكنولوجيا المتقدمة التهي تضـمن تقليل الآثار البيئيـة السـلبية

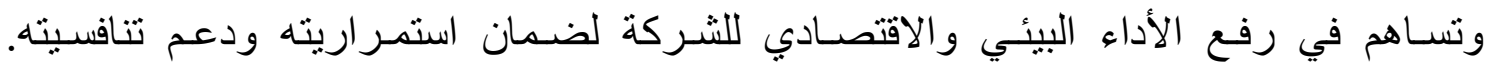

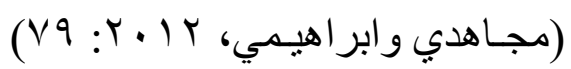
و عليه يعرف الباحثة الانتاج الأنظف بانه عبارة عن مجموعة من السياسات تطبيق على البى

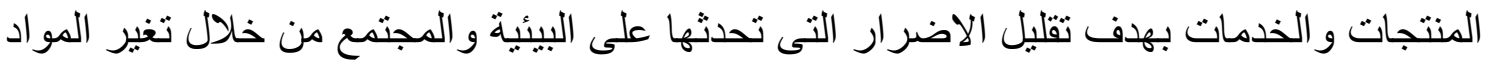

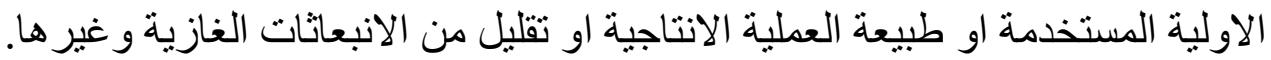
ثانياً. منافع الانتاج الأنظف: ان التغير في اتجاهات وممارسات الدول في تعاملها مع المخلفات

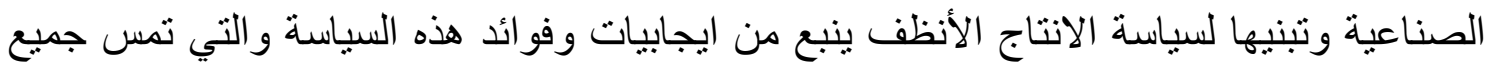

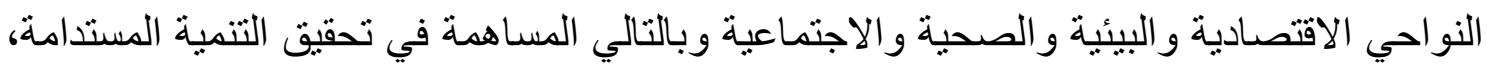
فالإنتاج الأنظف بساهم في تخفيض التكاليف المتعلقة بعمليات معالجة النفايات و التخلص منها

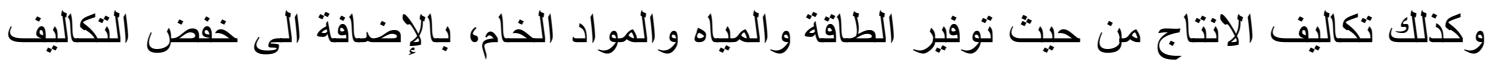

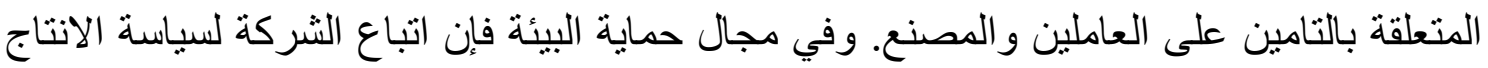
الأنظف ينعكس في فوائد تتراوح بين خفض كمية ونوعية الملوثات التي تطرح في البيئة الى

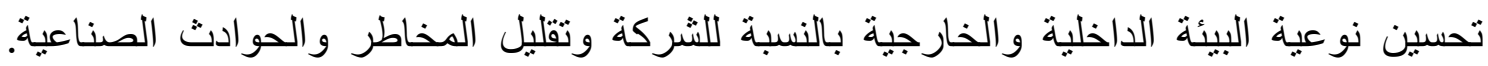

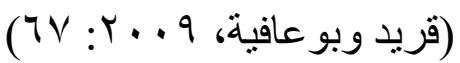

اما فيما يخص منافع الصحية عند تطبيق سياسة الانتاج الأنظف فانه يساهم في تقليل الامر اض الخطيرة التى تصاب العامليين بسبب انباع الغاز و الدخان من خلال العمليات الانتاجية الإنية التى تقوم بها الثركات، اما بالنسبة للمز ايا الاجتماعية من تطبيق سياسة الانتاج الأنظف فانه لهاع يساهم في حماية المجتمع التى تعمل الثركة في محيطه من الامر اض الخطيرة الى جانب تكوين صورة جيدة للثركة امام انظار المجتمع. ثالثثاً. اهداف الانتاج الأنظف: ان الهدف الاشمل لتطبيق سياسة الانتاج الأنظف هو العمل بصورة

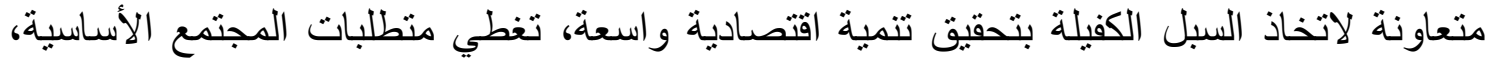

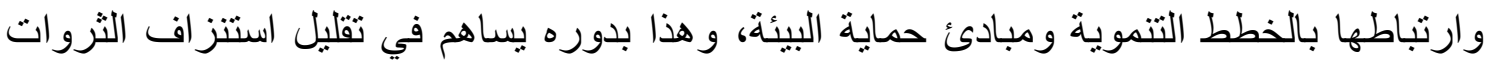
الطبيعية وزيادة الانتاج وترشيد في استخدام الطاقة والماء وتحسين جودة المنتج وزيادة ولئه القدرة

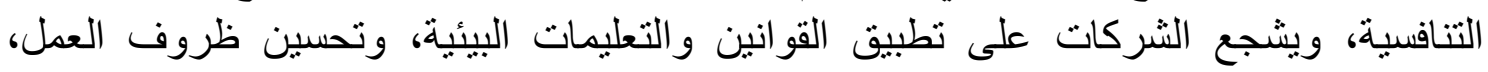




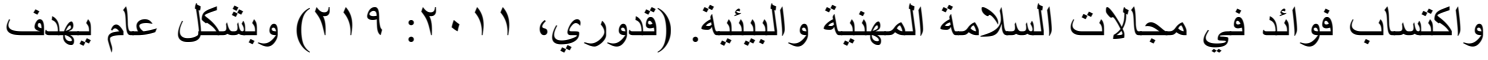

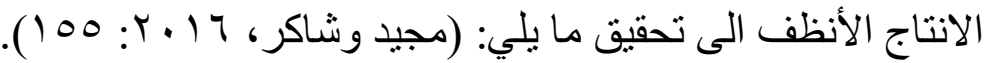

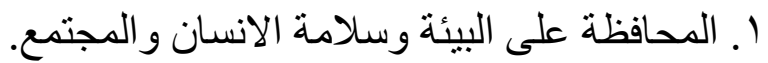

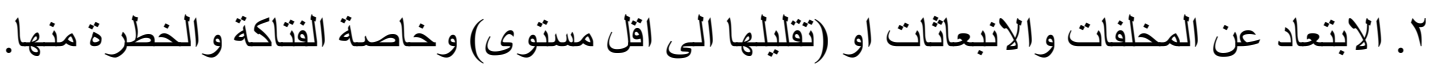

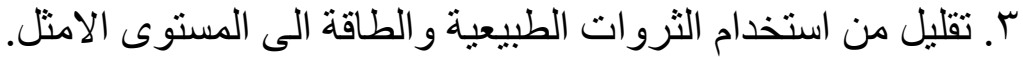
ع. الوصول الى اعلى مسنويات الجودة والانتاج و الربح المادي.

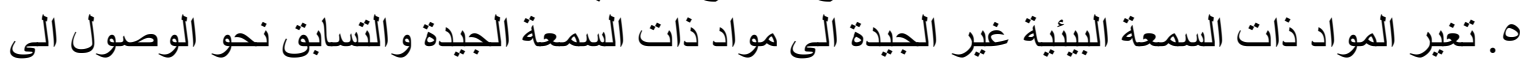

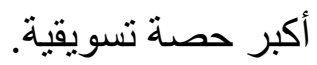
7. زيادة حصة هذه الصناعات في الاسو اق العاله العالمية. V. تجنب الثركات للمخاطر البيئية.

رابعاً. متطلبات الاتتاج الأنظف: ان نظام الانتاج الأنظف يتطلب استخدام نوع من التكنولوجيا

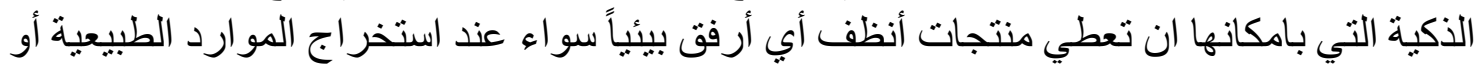

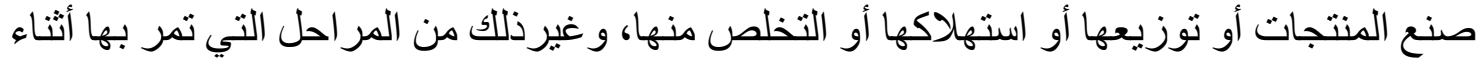

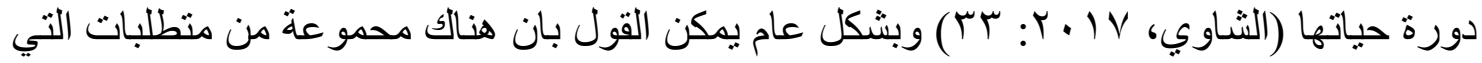

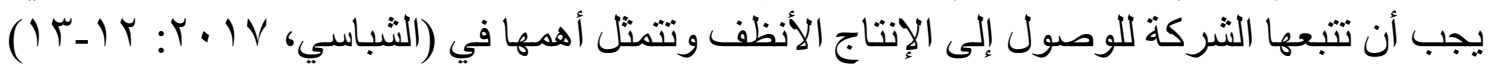

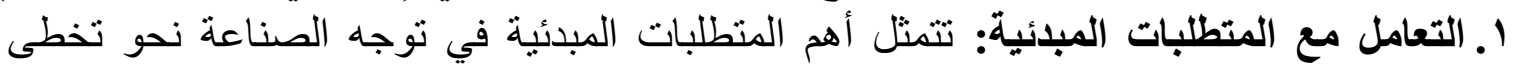
العوائق المعرفية والفنية من خلال الاعتماد على التحفيز الإيجابي كخطوة أولى للتشجيع على تبني الإنتاج الأنظف والتي منها تقديم دعم لمدخلات الإنتاج أو تقديم قروض ميسرة الإني للتكنولوجيات النظيفة الى جانب تحسين الأداء البيئي من خلال تنفيذ نظم الإدارة البيئية، وتبني شهادة الإنيأ الإدارة البيئية الآيزو واستخدام مو اد صديقة للبيئة في عملية الإنتاج من خلال استخدام مو اد بديلة تكون أقل خطورة على الإنسان و البيئة. ץ. اعتماد تقتيتي إعادة الاستخدام وإعادة التدوير للمخلفات: يقصد بتقنية إعادة الاستخدام الاستخدام

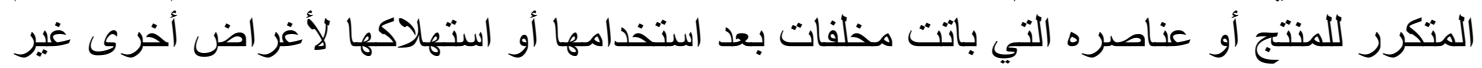

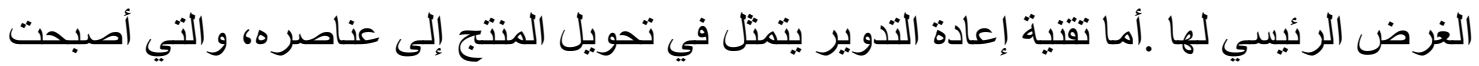

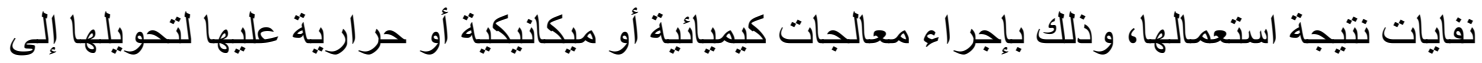

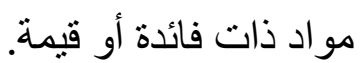

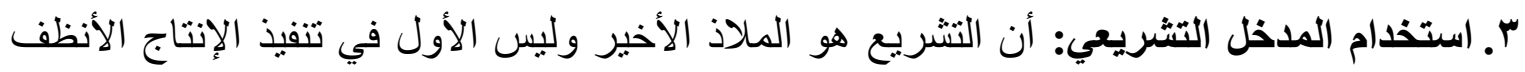

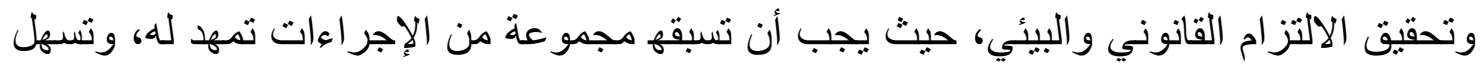

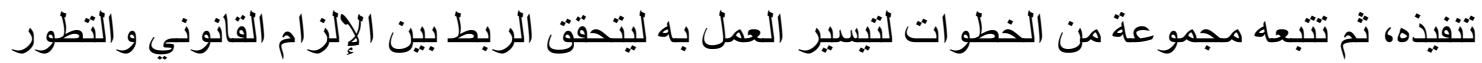

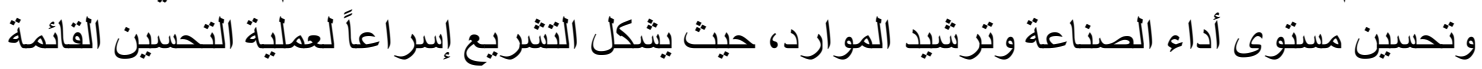

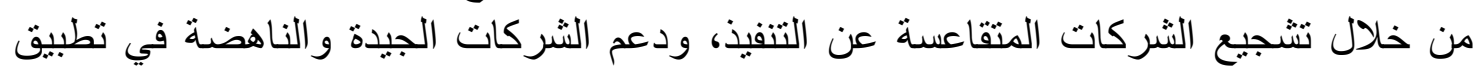

\section{المحور الثالث: الافصاح البيئي وسياسة الانتاج الأنظف} الإنتاج الأنظف. مناف.

أولاً. ركائز الانتاج الأنظف: يتم تطبيق سياسة الانتاج الأنظف عن طريق مجموعة من

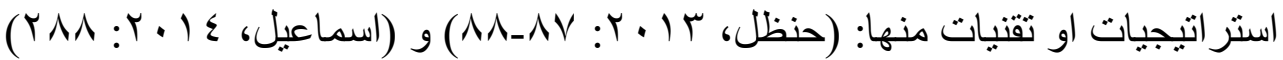

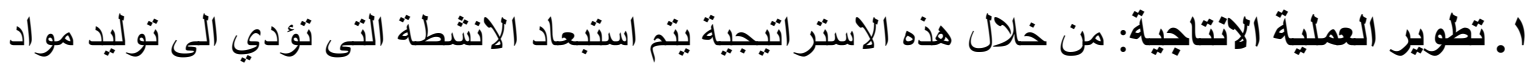
سامة مضرة بصحة الانسان أو البيئة وحسب نظام الانتاج الذي تلتبعه الثركة في عملياتها 
الانتاجية، فاتباع نظام الانتاج غير اليدوي واعتماد تقنية التحكم سيؤدي الى التوفير في الطاقة

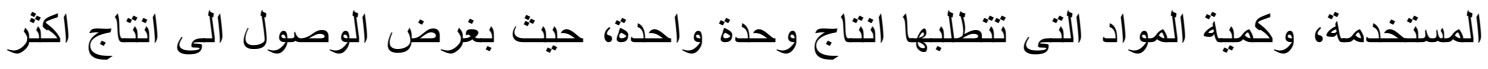

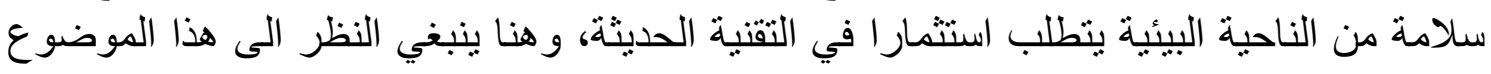

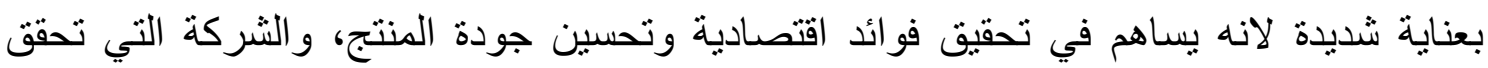

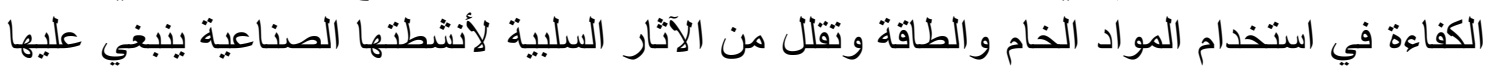
تغيير تقنياتها الانتاجية او تكيفها لتكون اكثر انسجاما مع ذلك الكوات الهدف.

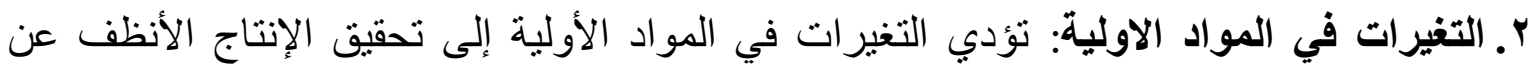

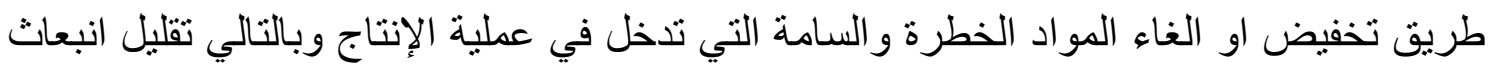

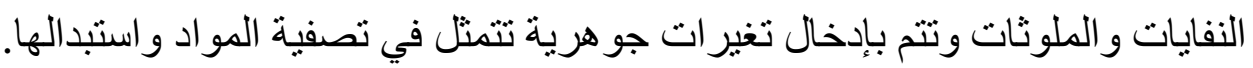

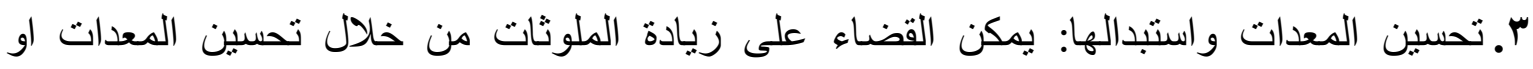
استبدالها وينتج عن هذه الخطوة تكنولوجيا حديثة ذات قدرة عالية في الانتاج وذات انبعاث اقل

؛ـ التغيرات في تكوين المنتج: وهي تللك التغير ات التي تجري على مكونات المنتج بهدف تقليل من

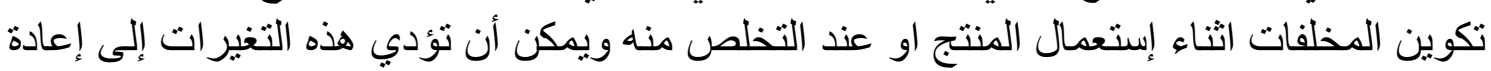

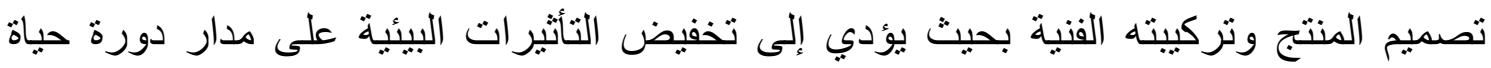
المنتج، وتتم اجر اء هذه التغير ات من خلال التغير في مو اصفات الجودة، التغير في مكونات المنتج، التغير ات في المنتج او استبداله. •ـ التقليص وإعادة الاستخدام والتدوير: نشير هذه المصطلحات إلى منع توليد النفايات من مصادر ها

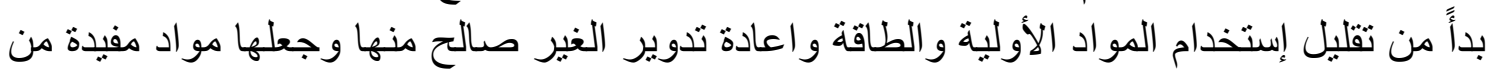
خلال مجموعة من المعالجات، أي بمعنى الإستخدام المتكرر للمنتج من خلال تغيير استخدامها

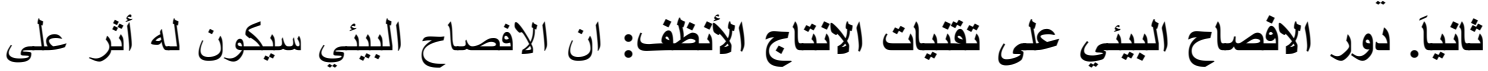

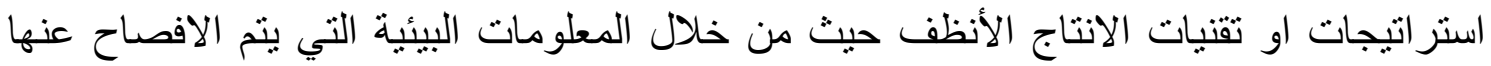
توضح هل ان هناك انشطة او ملوث للبيئة يتطلب استبداله بإنتاج انظف ام لا، فعلى سبيل المثال

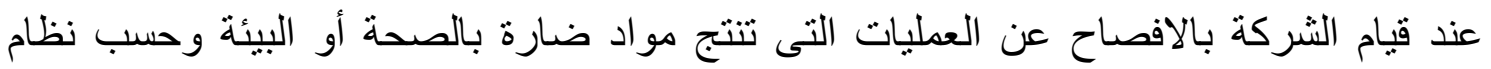

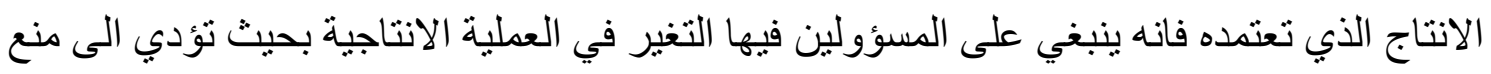
حدوث دخان او غاز ات ضارة والتى تؤثر على صحة الانسان وذلك من خلان الأل استبدالها بانتاج

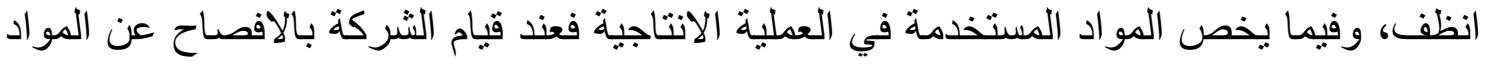

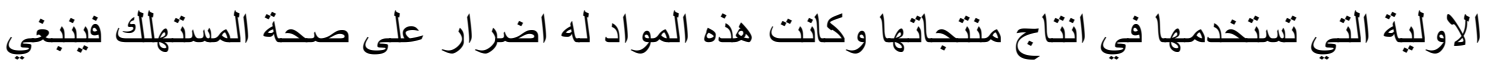

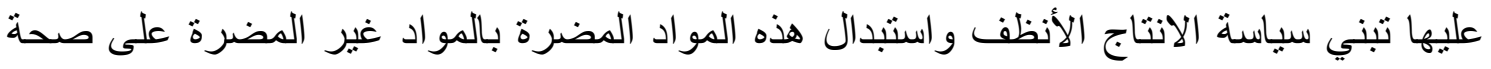

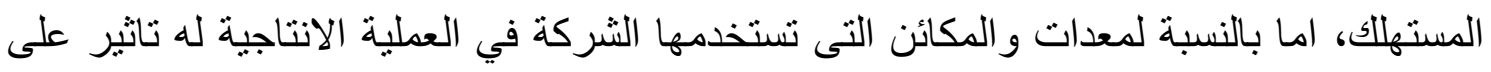

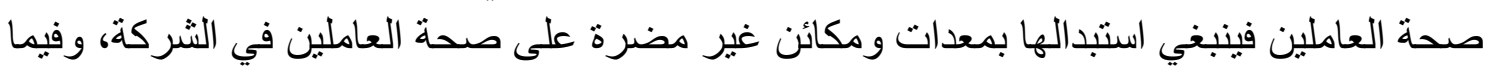

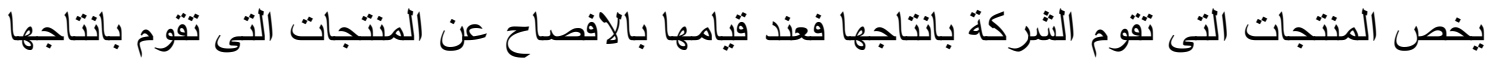

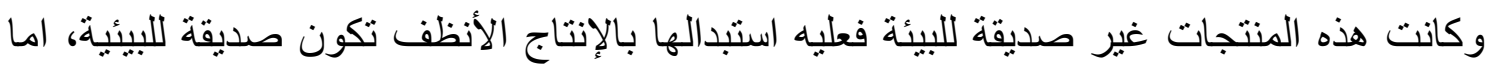
بالنسبة لاعادة تدوير المخلفات فعند قيام الثركة بالافصاح عن كيفية اعادة تدوير المخلفات وكانت عملية تدوير مضرة على صحة العاملين والمجتمع التي تعمل الثركة في محيطه فعليه استبدالها 
بانتاج انظف وذللك من خلال ايجاد حل لكيفية تدوير هذه المخلفات بحيث لا تؤثر على صحة العاملين و المجتمع التي تعمل الثركة في محيطه.

\section{المحور الرابع: الجانب التطبيقي فئني}

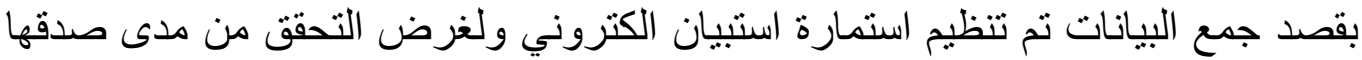

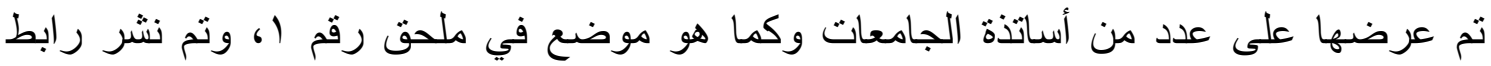

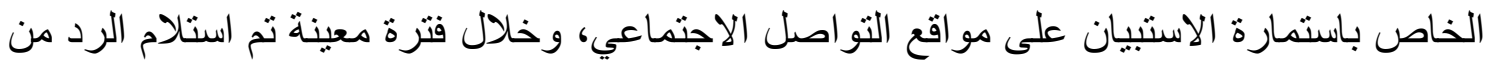

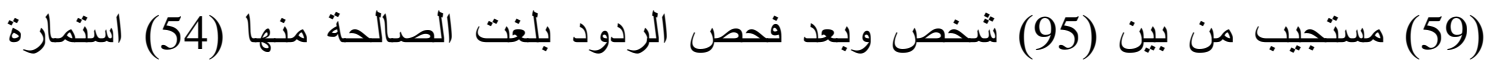
وبنسبة 92\% تقريباً، وبعد تفريغ محتويات الاستمار وات الصالحة تم معالجنها من خلال البرنامج SPSS وكانت المعالجة على النحو التالي:

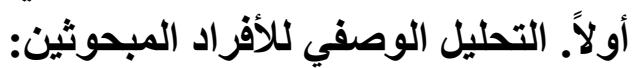

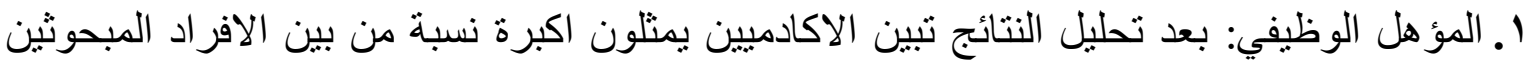

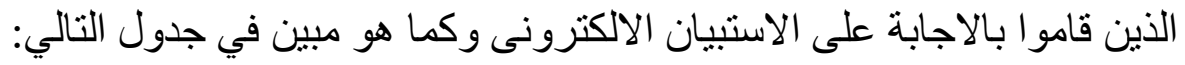

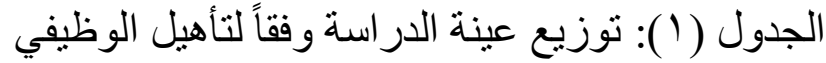

\begin{tabular}{|c|c|c|}
\hline النسبة المئوية & التكرارات & المؤهل الوظيفي \\
\hline$\% 33$ & 18 & مدير الثركة \\
\hline$\% 48$ & 26 & أكاديمي \\
\hline$\% 19$ & 10 & مهندس \\
\hline$\% 100$ & 54 & الدجموع \\
\hline
\end{tabular}

من خلال الجدول يتضح ان نسبة (48\%) من عينة الدراسة هم من الأكاديميين و الذين

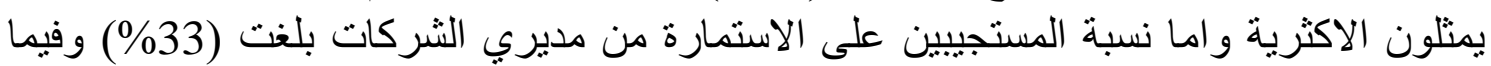

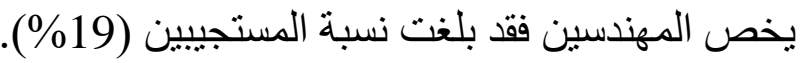

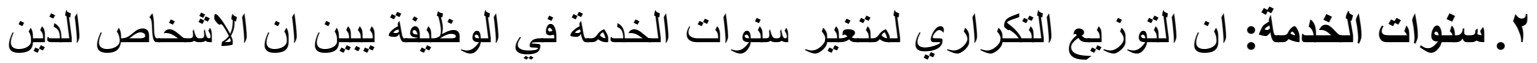

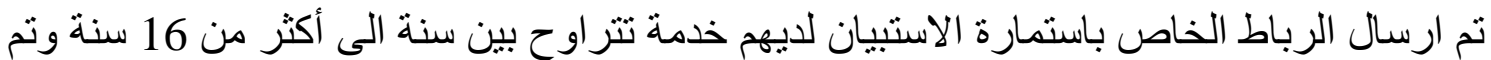
عرض النتائج في الجدول الآتي: الجدول (r): نوزيع عينة الدراسة وفقاً لسنوات الخدمة

\begin{tabular}{|c|c|c|}
\hline النسبة المئوية & التكرارات & مدة الخدمة \\
\hline$\% 17$ & 9 & 5-1 سنة \\
\hline$\% 35$ & 19 & 6-10 سنة \\
\hline$\% 28$ & 15 & 15-11 سنة \\
\hline$\% 20$ & 11 & 16 فأكثر \\
\hline$\% 100$ & 54 & المجموع \\
\hline
\end{tabular}

r. المؤهل العلمي: فيما يخص المؤهل العلمي تم ارسال الر ابط الخاص باستمارة الاستبانة الى حاملي

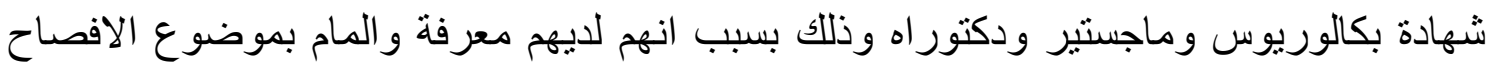

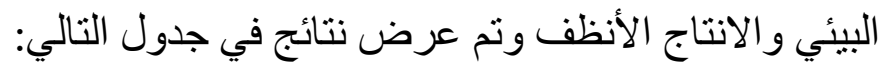




\begin{tabular}{|c|c|c|}
\hline النسبة المئوية & التكرارات & المؤهل العلمي \\
\hline$\% 22$ & 12 & بكالوريوس \\
\hline$\% 48$ & 26 & ماجستير \\
\hline$\% 30$ & 16 & دكتور اه \\
\hline$\% 100$ & 54 & المجموع \\
\hline
\end{tabular}

يثير الجدول اعلاه ان نسبة حاملي البكالوريوس بلغت (22\%) في حين بلغت حاملي شهادة (48\%) و الذي يمثل أكبر نسبة من المستجيبين اما فيما يخص نسبة المستجيبين من حاملي شهادة دكتور اه بلغت (030\%) (18).

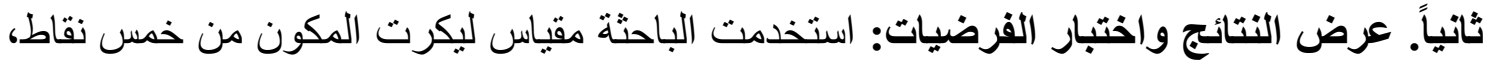

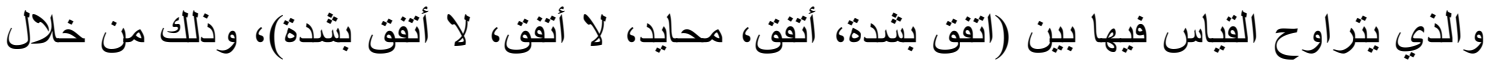

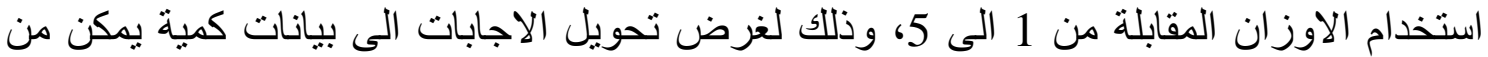

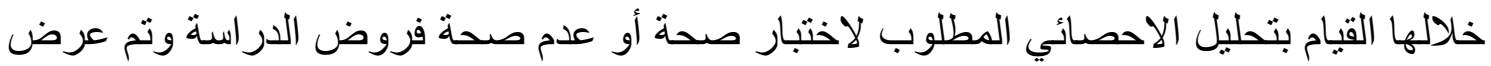
النتائج في الجداول التالية: الجدول (§): تحليل أسئلة الاستبانة حول الافصاح عن الأنشطة البيئية الخاصة بطبيعة العملية الإنتاجية

\begin{tabular}{|c|c|c|c|c|c|c|c|c|c|c|c|c|}
\hline \multirow{3}{*}{ المعيازي } & \multirow{3}{*}{ الحمابي } & \multicolumn{10}{|c|}{ الاجابات } & \multirow{3}{*}{ المتغيرات } \\
\hline & & \multicolumn{2}{|c|}{ لا أتفى بشدة } & \multicolumn{2}{|c|}{ لا أتفق } & \multicolumn{2}{|c|}{ محالِ } & \multicolumn{2}{|c|}{ أَفْقى } & \multicolumn{2}{|c|}{ أتفقى بشُدة } & \\
\hline & & $\%$ & التكراز & $\%$ & |التكرار & $\%$ & التكرار & $\%$ & التكرار & $\%$ & التكراز & \\
\hline 1.46 & 3.89 & 7.41 & 4 & 18.52 & 10 & 11.11 & 6 & 3.70 & 2 & 59.26 & 32 & $\mathrm{X} 1$ \\
\hline 0.66 & 4.06 & 1.85 & 1 & 1.85 & 1 & 1.85 & 1 & 77.78 & 42 & 16.67 & 9 & $\mathrm{X} 2$ \\
\hline 1.03 & 3.13 & 11.11 & 6 & 9.26 & 5 & 11.11 & 6 & 55.56 & 30 & 12.96 & 7 & $\mathrm{X} 3$ \\
\hline 1.27 & 2.81 & 11.11 & 6 & 40.74 & 22 & 20.37 & 11 & 11.11 & 6 & 16.67 & 9 & $\mathrm{X} 4$ \\
\hline 1.47 & 3.80 & 7.41 & 4 & 20.37 & 11 & 12.96 & 7 & 3.70 & 2 & 55.56 & 30 & $\mathrm{X} 5$ \\
\hline 1.18 & 3.54 & \multicolumn{4}{|c|}{$\% 25.93$} & \multicolumn{2}{|c|}{$\% 11.48$} & \multicolumn{4}{|c|}{$\% 62.59$} & Av \\
\hline
\end{tabular}

يبين الجدول اعلاه اجابات افر اد عينة الدر اسة، حيث ان نسبة المئوية للمو افقين (أتفق بثدة

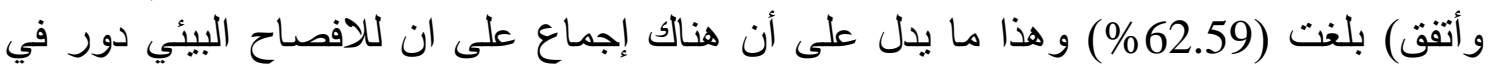
اعتمادية الانتاج فيما يخص طبيعة العملية الانتاجية ونسبة غير المبات المنأكدين (المحايدين) بلغت

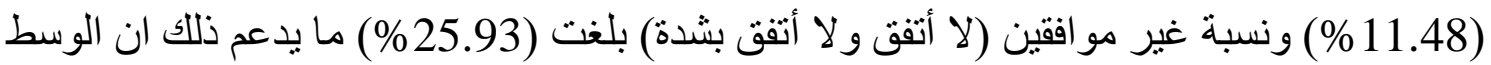

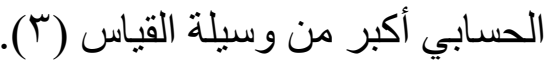

الجدول (0): تحليل أسئلة الاستبانة حول الأنشطة البيئية الخاصة بتغير ات في المواد الأولية

\begin{tabular}{|c|c|c|c|c|c|c|c|c|c|c|c|c|}
\hline \multirow{3}{*}{ الإحيراف } & \multirow{3}{*}{ الحسابي } & \multicolumn{10}{|c|}{ الاجابات } & \multirow{3}{*}{ المنتفِرات } \\
\hline & & \multicolumn{2}{|c|}{ لا أنفى بشدة } & \multicolumn{2}{|c|}{ لا أتفق } & \multicolumn{2}{|c|}{ محايد } & \multicolumn{2}{|c|}{ أنتفق } & \multicolumn{2}{|c|}{ أتفى بثدة } & \\
\hline & & $\%$ & التكزار & $\%$ & ألتكرار & $\%$ & التكزار & $\%$ & التكرار & $\%$ & التكرار & \\
\hline 1.31 & 3.63 & 7.41 & 4 & 18.52 & 10 & 9.26 & 5 & 33.33 & 18 & 31.48 & 17 & $\mathrm{X} 6$ \\
\hline 1.36 & 3.63 & 7.41 & 4 & 20.37 & 11 & 11.11 & 6 & 24.07 & 13 & 37.04 & 20 & $\mathrm{X} 7$ \\
\hline 0.81 & 3.94 & - & - & - & - & 40.74 & 22 & 35.19 & 19 & 24.07 & 13 & $\mathrm{X} 8$ \\
\hline 0.81 & 4.61 & - & - & 1.85 & 1 & 5.56 & 3 & 18.52 & 10 & 74.07 & 40 & $\mathrm{X} 9$ \\
\hline 1.38 & 3.30 & 9.26 & 5 & 25.93 & 14 & 14.81 & 8 & 24.07 & 13 & 25.93 & 14 & $\mathrm{X} 10$ \\
\hline 1.13 & 3.82 & \multicolumn{4}{|c|}{$\% 18.15$} & \multicolumn{2}{|c|}{$\% 16.30$} & \multicolumn{4}{|c|}{$\% 65.55$} & Av. \\
\hline
\end{tabular}


يشير الجدول السابق بإن الغالبية والتي تمثل (65.55\%) من بين المستجيبين موافقين

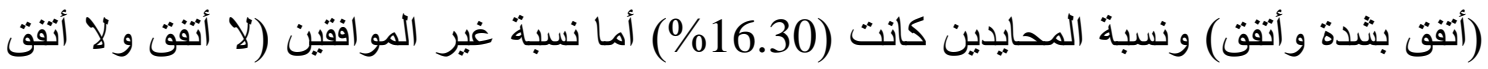

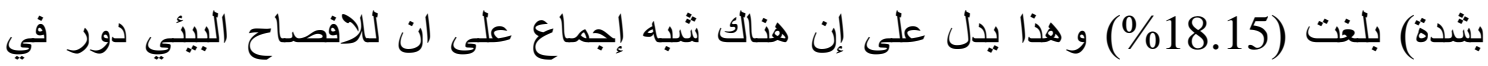

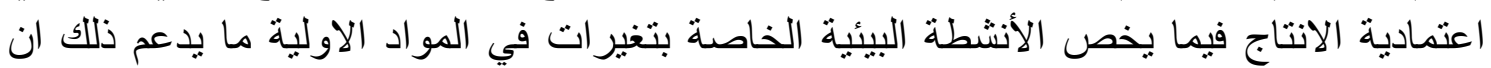

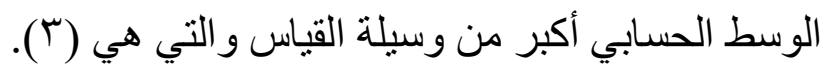
الجدول (؟): تحليل أسئلة الاستبانة حول الأنشطة البيئية الخاصة بتطوير المعدات واستبدالها

\begin{tabular}{|c|c|c|c|c|c|c|c|c|c|c|c|c|}
\hline \multirow{3}{*}{ المباري } & \multirow{3}{*}{ الحسابي } & \multicolumn{10}{|c|}{ الاجبات } & \multirow{3}{*}{ المتنيزات } \\
\hline & & \multicolumn{2}{|c|}{ 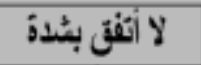 } & \multicolumn{2}{|c|}{ لا أتفق } & \multicolumn{2}{|c|}{ محايد } & \multicolumn{2}{|c|}{ أتفنى } & \multicolumn{2}{|c|}{ أتفقى بُشدة } & \\
\hline & & $\%$ & النكرار & $\%$ & التكرار & $\%$ & التكرار & $\%$ & التكرار & $\%$ & النكراز & \\
\hline 0.97 & 2.93 & 11.11 & 6 & 16.67 & 9 & 40.74 & 22 & 31.48 & 17 & - & - & X11 \\
\hline 1.12 & 3.26 & - & - & 31.48 & 17 & 31.48 & 17 & 16.67 & 9 & 20.37 & 11 & $\mathrm{X} 12$ \\
\hline 1.30 & 3.69 & 7.41 & 4 & 16.67 & 9 & 9.26 & 5 & 33.33 & 18 & 33.33 & 18 & $\mathrm{X} 13$ \\
\hline 1.21 & 3.83 & 3.70 & 2 & 14.81 & 8 & 9.26 & 5 & 30.04 & 20 & 35.19 & 19 & X14 \\
\hline 1.11 & 3.98 & 3.70 & 2 & 9.26 & 5 & 11.11 & 6 & 30,04 & 20 & 38.89 & 21 & X15 \\
\hline 1.14 & 3.54 & & $\% 2$ & & & & & & & & & Av. \\
\hline
\end{tabular}

يثير الجدول السابق النسب المئوية للإجابات عن الأسئلة الى جانب الوسط الحسابي

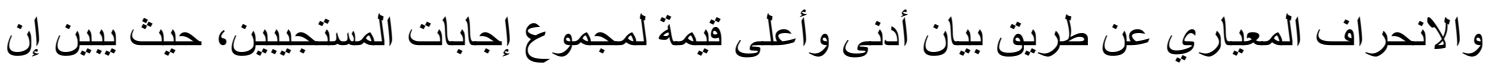

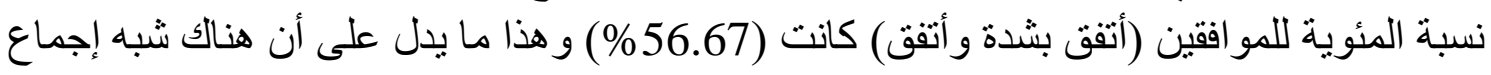

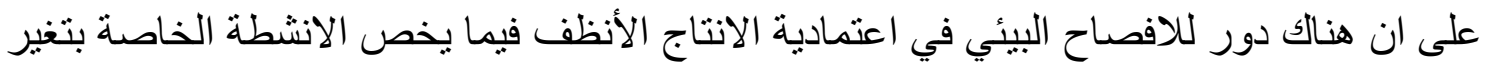

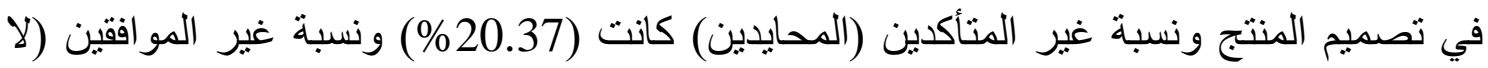

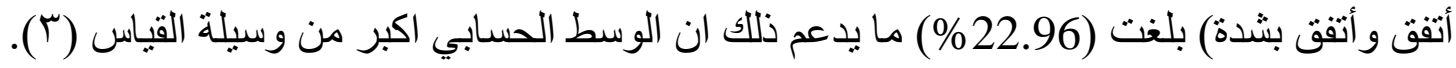

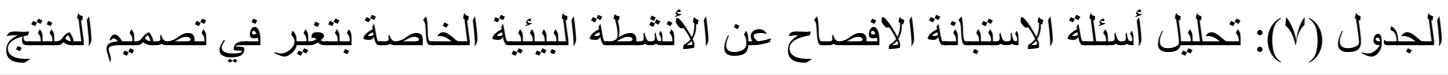

\begin{tabular}{|c|c|c|c|c|c|c|c|c|c|c|c|c|}
\hline \multirow{3}{*}{ المبجري } & \multirow{3}{*}{ الحسابي } & \multicolumn{10}{|c|}{ الاجابات } & \multirow{3}{*}{ المنتيرات } \\
\hline & & \multicolumn{2}{|c|}{ لا أتفى بثداة } & \multicolumn{2}{|c|}{ لا آتفَّ } & \multicolumn{2}{|c|}{ مداليّا } & \multicolumn{2}{|c|}{ أتفَّى } & \multicolumn{2}{|c|}{ أنفق بشدة } & \\
\hline & & $\%$ & النكرار & $\%$ & التكرار & $\%$ & التكرار & $\%$ & التكرار & $\%$ & التكرار & \\
\hline 1.00 & 3.61 & 3.70 & 2 & 16.67 & 9 & 3.70 & 2 & 66.67 & 36 & 9.26 & 5 & X16 \\
\hline 1.21 & 3.78 & 5.56 & 3 & 3.70 & 2 & 40.74 & 22 & 7.41 & 4 & 42.59 & 23 & $\mathrm{X} 17$ \\
\hline 1.07 & 3.02 & - & - & 38.89 & 21 & 30.04 & 20 & 9.26 & 5 & 14.81 & 8 & $\mathrm{X} 18$ \\
\hline 1.82 & 3.24 & 35.19 & 19 & 1.85 & 1 & 12.96 & 7 & 3.70 & 2 & 46.30 & 25 & X19 \\
\hline 0.88 & 3.70 & 3.70 & 2 & 7.41 & 4 & 12.96 & 7 & 66.67 & 36 & 9.26 & 5 & $\mathrm{X} 20$ \\
\hline 1.20 & 3.47 & \multicolumn{4}{|c|}{$\% 23.33$} & & 1.48 & \multicolumn{4}{|c|}{$\% 55.19$} & Av. \\
\hline
\end{tabular}

وييين الجدول اعلاه ان نسبة المئوية للمو افقين (أنفق بشدة و أنفق) بلغت (55.19\%) و هذا

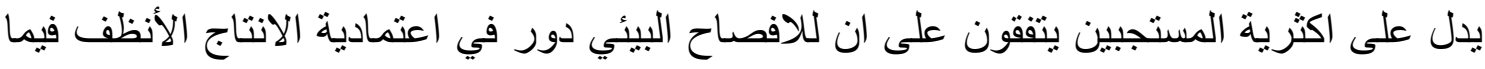

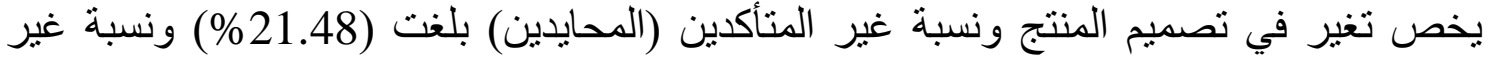
متفقين (لا أتفق و لا أنقق بشدة) بلغت (23.33\%) ما يدعم ذللك هو أن المتوسط الحسابي أكبر من 
الجدول (^): تحليل أسئلة الاسنبانة الافصاح عن الأنشطة البيئية الخاصة بإدارة المخلفات و النفايات

\begin{tabular}{|c|c|c|c|c|c|c|c|c|c|c|c|c|}
\hline \multirow{3}{*}{ المعيلزي } & \multirow{3}{*}{ التسابي } & \multicolumn{10}{|c|}{ الاجابات } & \multirow{3}{*}{ المتفغرات } \\
\hline & & \multicolumn{2}{|c|}{ لا أنتفى بشُدة } & \multicolumn{2}{|c|}{ لا أنفقى } & \multicolumn{2}{|c|}{ محايد } & \multicolumn{2}{|c|}{ أنفى } & \multicolumn{2}{|c|}{ أتفى بشدأ } & \\
\hline & & $\%$ & التكرار & $\%$ & التكرار & $\%$ & التكرار & $\%$ & التكرار & $\%$ & التكرار & \\
\hline 1.05 & 4.09 & 3.70 & 2 & 7.41 & 4 & 5.56 & 3 & 42.59 & 23 & 40.74 & 22 & $\mathrm{X} 21$ \\
\hline 1.32 & 2.39 & 40.74 & 22 & 3.70 & 2 & 40.74 & 22 & 5.56 & 3 & 9.26 & 5 & $\mathrm{X} 22$ \\
\hline 0.71 & 4.06 & 1.85 & 1 & 46.30 & 25 & 1.85 & 1 & 42.59 & 23 & 7.41 & 4 & $\mathrm{X} 23$ \\
\hline 1.89 & 3.85 & 1.85 & 1 & 1.85 & 1 & 50 & 27 & - & - & 46.30 & 25 & $\mathrm{X} 24$ \\
\hline 0.80 & 4.31 & 1.85 & 1 & 1.85 & 1 & 3.70 & 2 & 55.56 & 30 & 37.04 & 20 & $\mathrm{X} 25$ \\
\hline 1.15 & 3.74 & \multicolumn{4}{|c|}{$\% 22.22$} & \multicolumn{2}{|c|}{$\% 20.37$} & \multicolumn{4}{|c|}{$\% 57.41$} & Av. \\
\hline
\end{tabular}

يثير الجدول المذكور اعلاه الى اجابات افراد المستجيبين، حيث ان نسبة المئوية للمو افقين

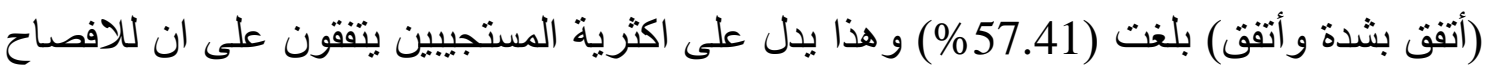

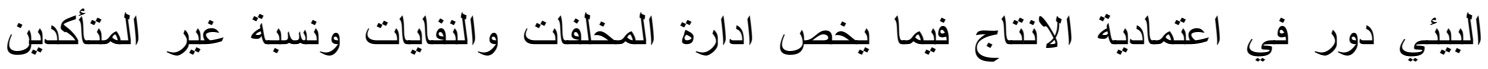
(المحايدين) بلغت (20.37\%) ونسبة غير الموافقين (لا أتفق ولا أتفق بشدة) بلغت (22.22\%)

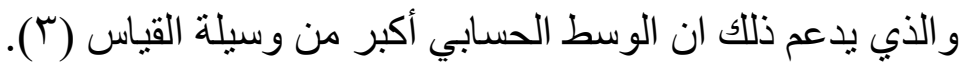

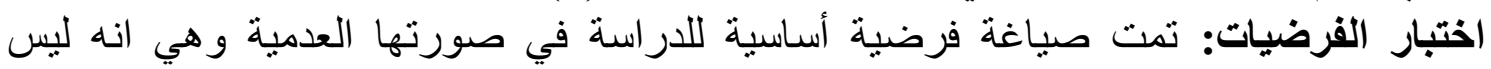
للافصاح البيئي دور في اعتمادية الانتاج الأنظف وتثفرع من هذه الفرضية الاساسية الفرضيات الفر عية التالية: الفرضية الفرعية الاولى: ان الافصاح عن الأنشطة البيئية الخاصة بطبيعة العملية الانتاجية ليس له

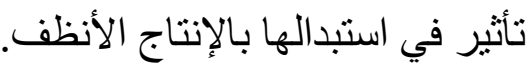

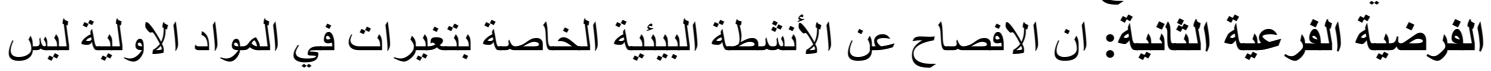
له تأثثر في استبدالها بالإنتاج الأنظف. الأهن. الفرضية الفرعية الثالثة: ان الافصاح عن الإنيد الأنشطة البيئية الخاصة بتطوير المعدات واستبدالها

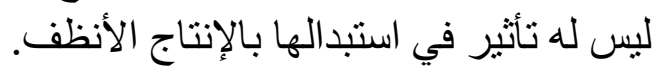
الفرضية الفرعية الرابعة: ان الافصاح عن الأنشطة البيئية الخاصة بتغير في تصميم المنتج ليس

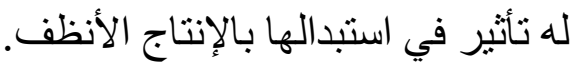

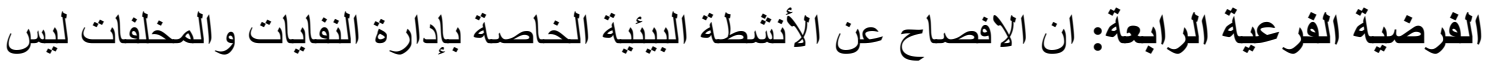
له تأثثر في استبدالها بالإنتاج الأنظف. ولغرض التأكد من صحة الفرضيات الفرعية اعلاه اعتمدت الباحثة على اختبار T. test وتم عرض النتائج في الجدول التالي: الجدول (9): نتائج اختبار الفرضيات الفرعية بموجب إختبار (T. test)

\begin{tabular}{|c|c|c|c|c|c|}
\hline الإحصائية & $\mathbf{T}$ & الانحراف المعياري & الحسابي الوسط & حجنة & المتغيرات \\
\hline 0.05 & 0.000 & 1.18 & 3.54 & 54 & F 1 \\
\hline 0.05 & 0.000 & 1.13 & 3.82 & 54 & F 2 \\
\hline 0.05 & 0.000 & 1.14 & 3.54 & 54 & F 3 \\
\hline 0.05 & 0.000 & 1.20 & 3.47 & 54 & F 4 \\
\hline 0.05 & 0.000 & 1.15 & 3.74 & 54 & F 5 \\
\hline
\end{tabular}


وكما يبين في الجدول السابق إن نتيجة اختبار T لجميع الفرضيات الفرعية هي (0.000)

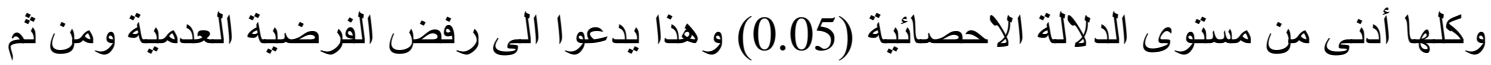
قبول الفرضية البديلة الرئيسية وهي ان هناك دور للإفصاح البيئي في اعتمادية تقنيات الانتاج

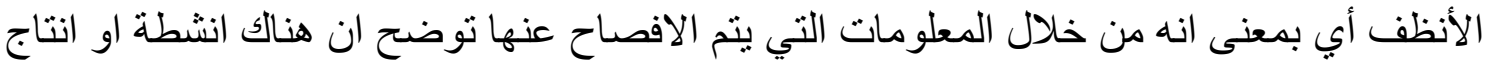
ملوث للبيئة يتطلب استبداله بإنتاج نظيف. بنه

\section{المحور الخامس: الاستثتاجات والتوصيات}

أولاً. الاستتتاجات: من خلال البحث و الدراسة توصلت الدراسة الى سلسلة من الاستتناجات من

ا. ان الافصاح البيئي عبارة عن عرض المعلومات البيئية والخاصة بالأنشطة الانتاجية التي تمارسها الثركة وذلك في القوائم و التقارير المالية وهذا يساعد مستخدمي تللك البيانات و المعلومات البيئية على تقييم مستوى اداء البيئي للشركة.

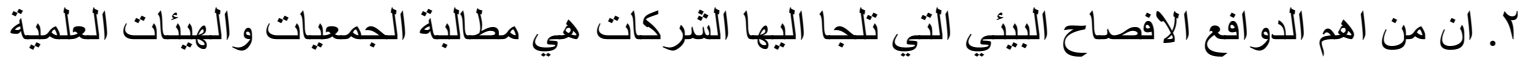

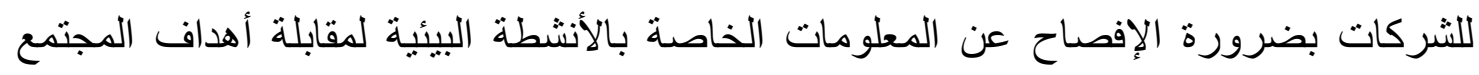
و الإحتياجات الجديدة له.

r. ان الانتاج الأنظف بانه عبارة عن مجموعة من سياسات تطبيق على المنتجات و الخدمات بهدف

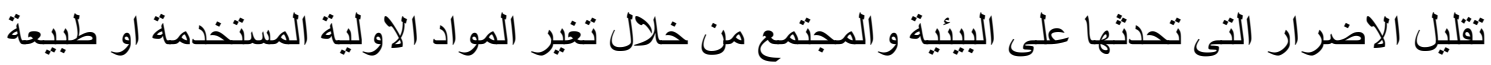
العملية الانتاجية او تقليل من الانبعانات الغازية و غير هائها

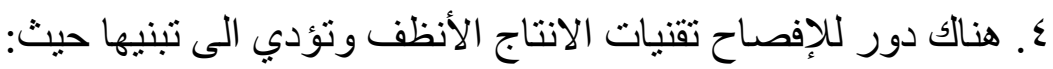
أ. ان الافصاح عن الأنشطة البيئية الخاصة بطبيعة العملية الانتاجية له تأثير في استبدالها بالإنتاج الأنظف. ب.ان الافصاح عن الأنشطة البيئية الخاصة بتغير في المواد الاولية له تأثير في استبدالها بالإنتاج الأنظف.

ج. ان الافصاح عن الأنشطة البيئية الخاصة باستبدال المعدات له تأثنير في استبدالها بالإنتاج الأنظف. د. ان الافصاح عن الأنشطة البيئية الخاصة بتغير في تصميم المنتج له تأثير في استبدالها بالإنتاج الأنظف. ه. ان الافصاح عن الأنشطة البيئية الخاصة بإدارة النفايات والمخلفات له تأثير في استبدالها بالإنتاج الأنظف.

ثانياً. التوصيات: بالاعتماد على الاستتتاجات التي توصل البها الدر اسة توصي الباحثة بما يلي: ا ـ قيام الثركات على انو اعها بالافصاح البيئي لما لها من عدة فوائد الذي يخصنا في هذا الدراسة هو

$$
\text { دور ها في تبني سياسة الانتاج الأنظف. }
$$

r. قيام الشركات بتطبيق سياسة الانتاج الأنظف لما لها من عدة مزايا من اهمها هو الحفاظ على البيئة

التى تعمل الثركة في محيطه الى جانب تحقيق الميزة التنافسية.

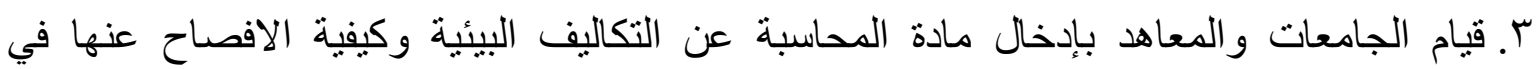
المناهج الدر اسية لما لها دور في زيادة الثقافة البيئية لدى الطلاب. بادهاب. 
المصادر

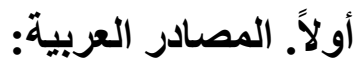

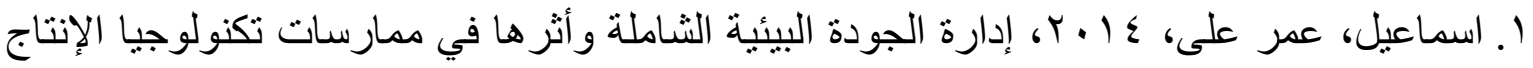

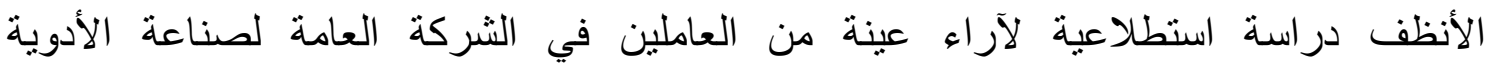

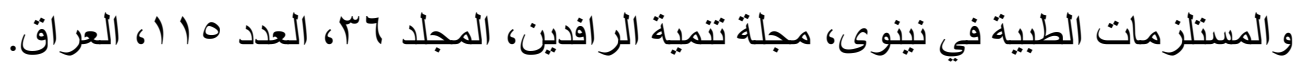

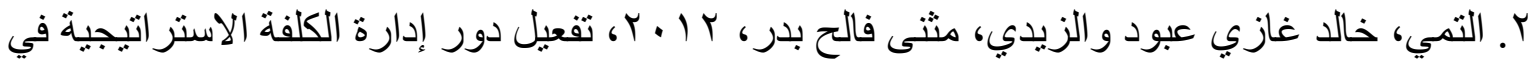

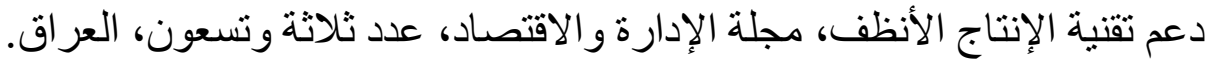

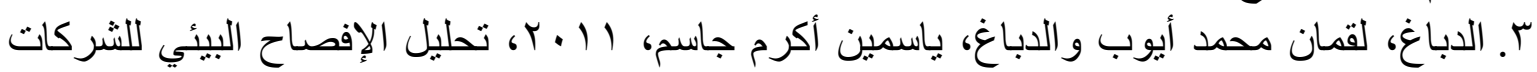

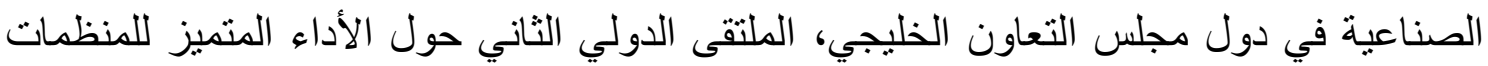

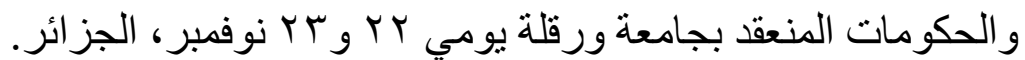

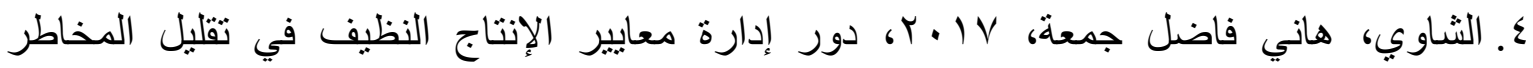
الاقتصادية و البيئية و الصحية وفقا لفلسفة (Jidoka) اليابانية بحث استطلاعي لآراء عينة من فنيي

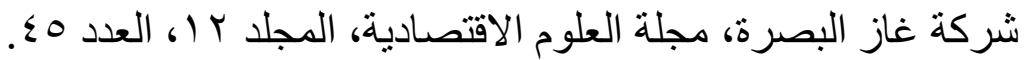

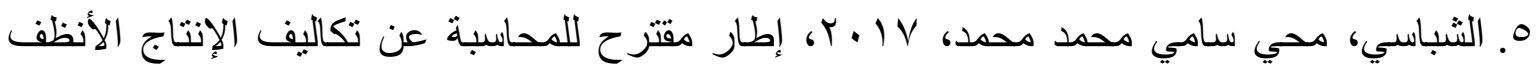
لاعم الميزة التنافسية في بيئة الأعمال الصناعية دراسة تطبيقية، أطروحة دكتور اه، كلية التجارة

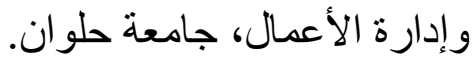

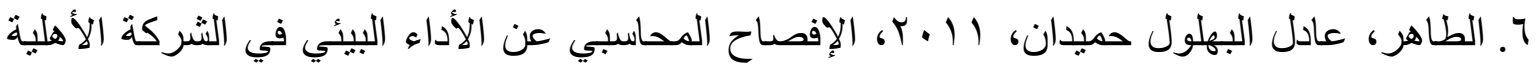

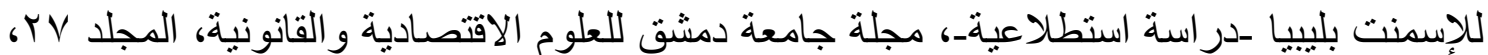

$$
\text { العدد (، سوريا. }
$$

V. حمد، منى عبدالله، ـ ا ـ r، أثر قياس التكاليف البيئية و الإفصاح عنها في رفع كفاءة الأداء البيئي

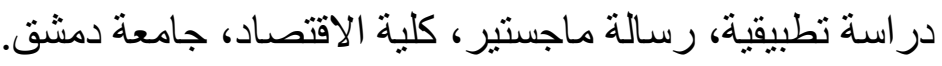

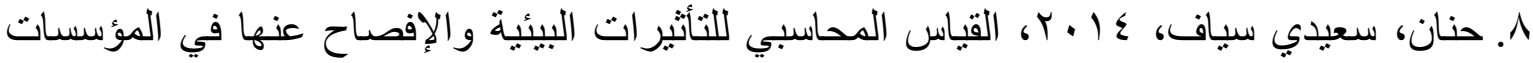
الصناعية در اسة حالة مؤسسة الإسمنت حامة بوزيان -SCHB- قسنطينة، رسالة ماجستير، كلية

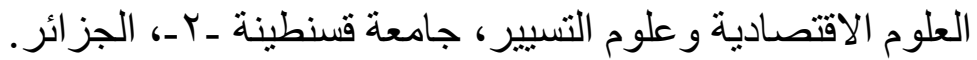

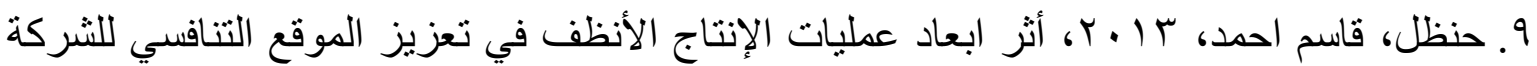

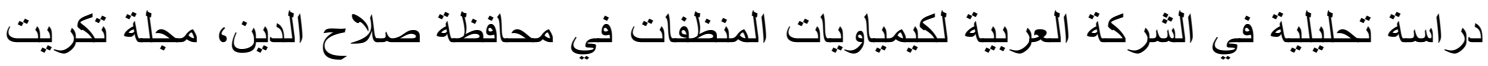

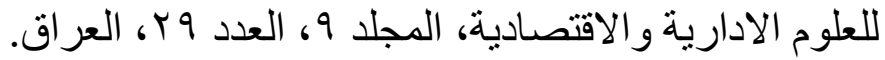
• 1 ـ عبدالسيد، ناظم حسن وسلطان، أياد شاكر ويوسف، زينب جبار ، 9 . . ب، المحاسبة البيئية: الإطار

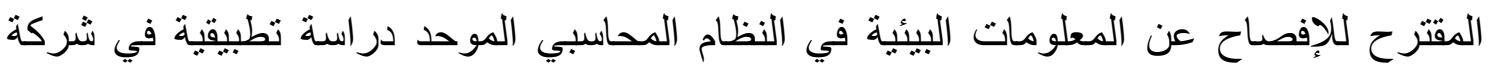

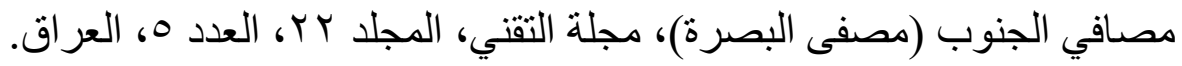

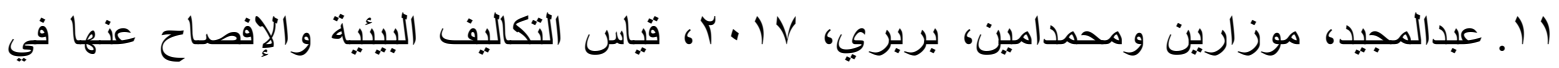

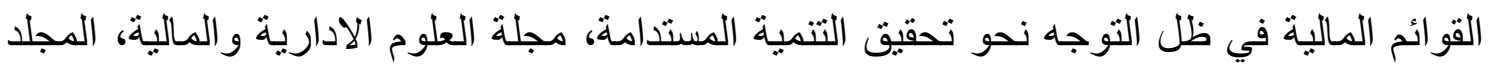

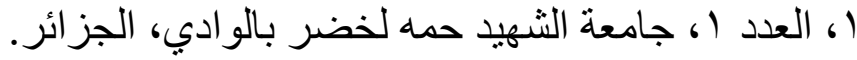

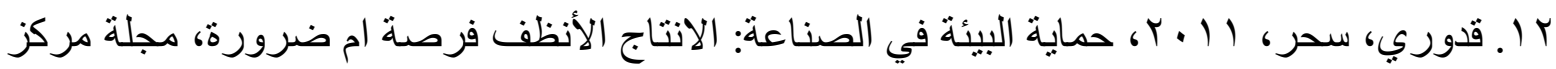

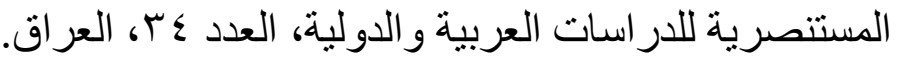


ب ا قريد، مصطفى وبوعافية، سمير، 9 . . Y، مدى مساهمة استراتيجية الانتاج الأنظف في تحقيق

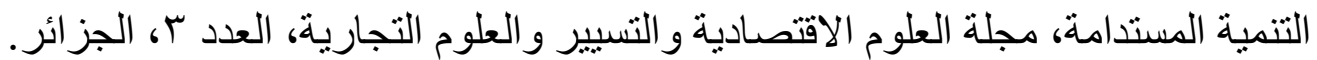

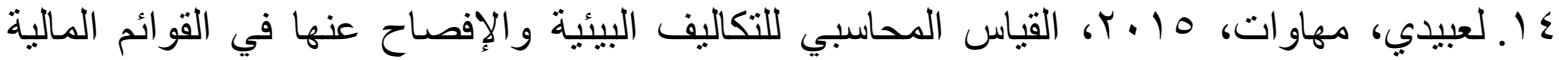

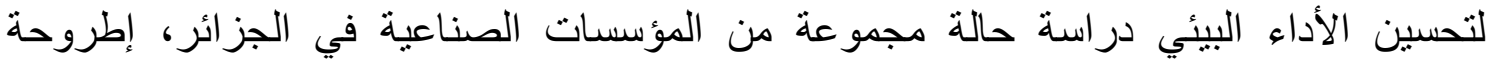

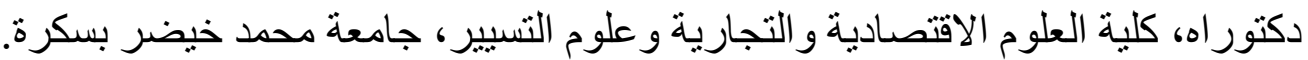

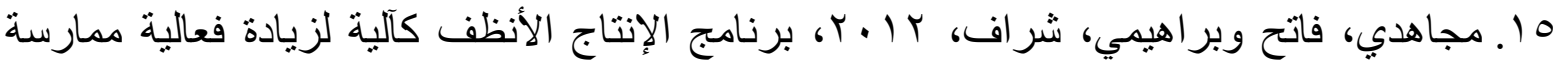
الإدارة البيئية ودعم الأداء البيئي للمؤسسة در اسة حالة مؤسسة الاسمنت ومشتقاته بالثشف، مجلة

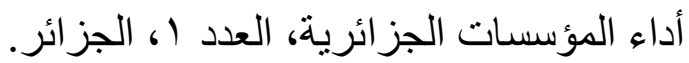

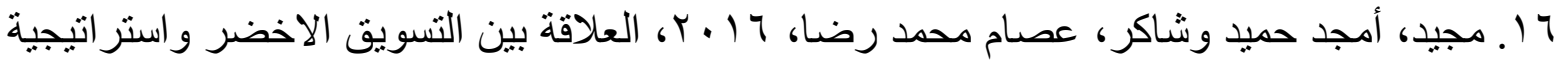
الانتاج الأنظف دراسة اسنطلاعية لآراء عينة في معمل سمنت كربلاء، مجلة كلية الادارة

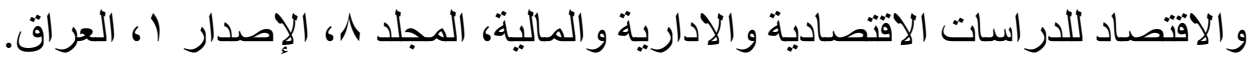

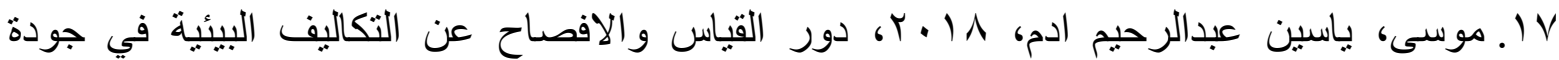
المعلومات المحاسبية دراسة ميدانية على عينة دن الشركات الصناعية العاملة في السودان، إطروحة دكتور اه، كلية الدراسات العليا، جامعة السودان للعلوم و التكنولوجيا. ثانياً. المصادر الأجنبية:

1. Dattane, Jemish and Devani, Darshan and Sahu, 2013, Cleaner Production of Vinyl Chloride Monomer (VCM), International Journal of Scientific \& Engineering Research, Volume 4, Issue 5.

2. Doorasamy, Mishelle, 2015, Identifying environmental and economic benefits of cleaner production in a manufacturing company: a case study of a paper and pulp manufacturing company in KwaZulu-Natal, Investment Management and Financial Innovations Journal, Volume 12, Issue 1,

3. Sief, Hanane Saidi, 2014, Accounting Framework to Measure the Environmental Costs and Disclosed in Industrials Companies-Case Study of Societe Cement Hamma Bouziane (SCHB) in Constantine, Chinese Business Review, Vol. 13, No. 6.

الملاحق

الملحق (1) اسماء السادة المحكمين لاستمارة الاستبيان

\begin{tabular}{|c|c|c|c|}
\hline 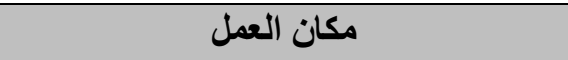 & اللاقب العلمي & الاسماء & 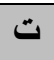 \\
\hline كلية الادارة و الاقتصاد/جامعة صلاح الدين & استاذ مساعد & يم يوسف حنا & 1 \\
\hline كلية الادارة والاقتصاد/جامعة صلاح الدين & استاذ مساعد & أ.م.دشتى خالد حمدامين & $r$ \\
\hline عحهد التقني الاداري/جامعة اربيل التقنية & استاذ مساعد & أ.م.رفز محمد صالح & $r$ \\
\hline
\end{tabular}

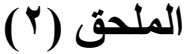

استمارة استبانة

تحيــة طيبة

نضع بين ايديكم الكريمة استمارة الاستبانة الخاصة بالدر اسة الموسوم (أثر الافصاح البيئي على اعتمادية الانتاج الأنظف در اسة استطلاعية) راجين الاجابة عن اسئلتها بكل موضو عية وحياد

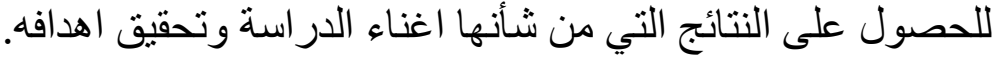
شاكرين تعاو نكم معنا خدمة للمسيرة العلمية 
ملاحظة: يرجى وضع علامة ( ل) في المربع الذي يمثل اجابتك وإذا كانت لديكم اية تعليقات او

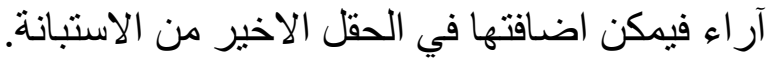

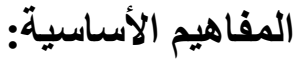
الافصاح البيئي: الافصاح البئئي بأنه عرض المعلومات البات البيئية والخاصة بالانشطة الانتاجية التى تمارسها الثركة وذللك في القوائم و التقارير المالية و هذا يساعد مستخدمي تللك البيانات و المعلومات البيئية على تقييم مستوى اداء البيئي للثركة. الانتاج الأنظف: عبارة عن مجموعة من تقنيات تطبيق على المنتجات و الخدمات بهدف تقليل

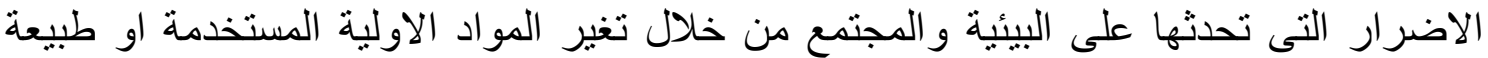

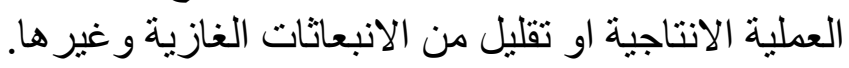

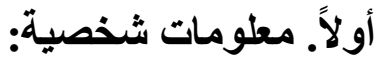

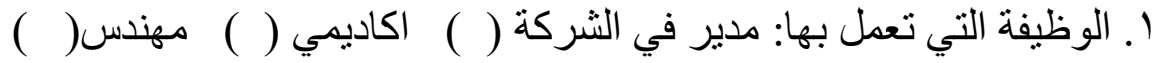

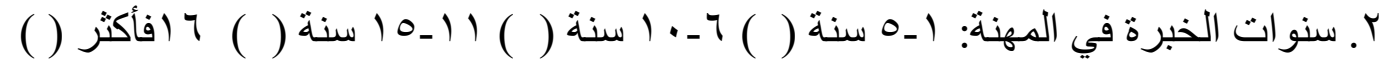

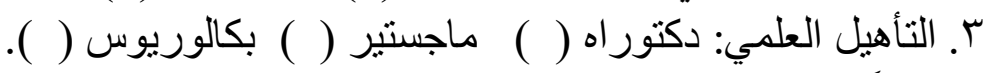

\begin{tabular}{|c|c|c|c|c|c|c|}
\hline \multicolumn{7}{|c|}{ المحور الأول: الافصاح عن الأنشطة البيئية الخاصة بطبيعة العملية الانتاجية ويتطلب استبدالها بالإنتاج الأنظف } \\
\hline ل أبثدة & أنقا & محايد & 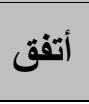 & 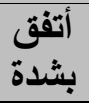 & \multicolumn{2}{|l|}{ الأسئلة } \\
\hline & & & & & 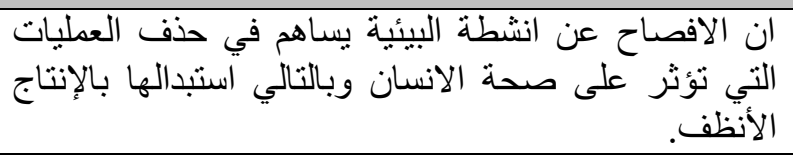 & 1 \\
\hline & & & & & 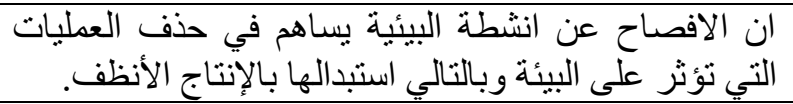 & r \\
\hline & & & & & 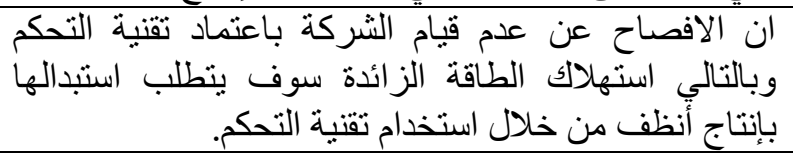 & $r$ \\
\hline & & & & & 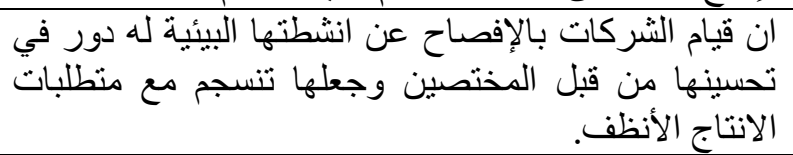 & $\varepsilon$ \\
\hline & & & & & 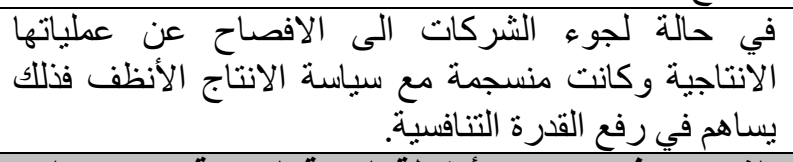 & 0 \\
\hline \multicolumn{7}{|c|}{ المحور الثاني: الافصاح عن الأنشطة البيئية الخاصة بتغيرات المواد الاولية ويتطلب استبدالها بالإنتاج الأنظف } \\
\hline \multirow[t]{6}{*}{ 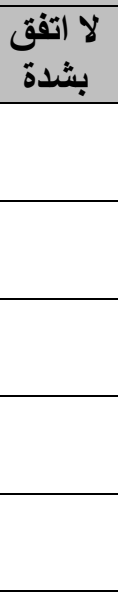 } & 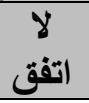 & محايد & 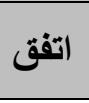 & 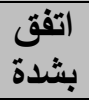 & \multicolumn{2}{|l|}{ الأسئلة } \\
\hline & & & & & 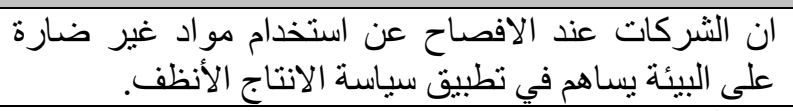 & 7 \\
\hline & & & & & 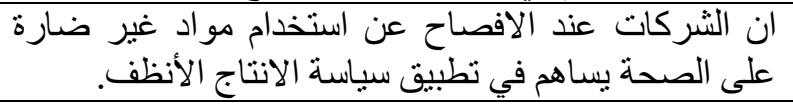 & V \\
\hline & & & & & 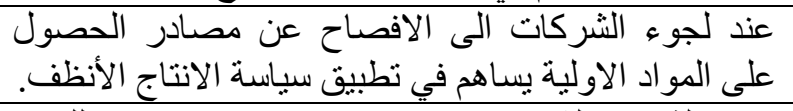 & $\wedge$ \\
\hline & & & & & 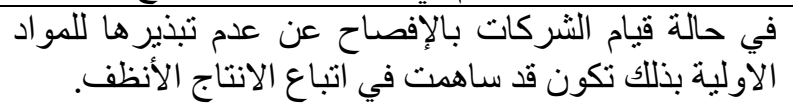 & 9 \\
\hline & & & & & 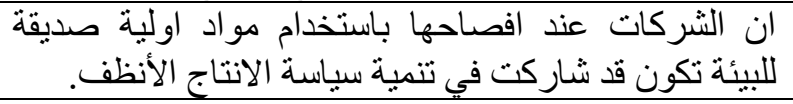 & 1. \\
\hline
\end{tabular}




\begin{tabular}{|c|c|c|c|c|c|c|}
\hline \multicolumn{7}{|c|}{ المحور الثالث: الافصاح عن الأنشطة البيئية الخاصة بتظوير المعدات ويتطلب استبدالها بالإنتاج الأنظف } \\
\hline لالأنقق & 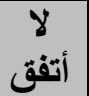 & محايد & أتقق & بشدة أنقة & \multicolumn{2}{|l|}{ 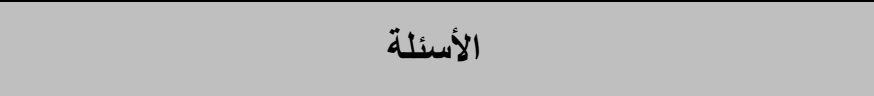 } \\
\hline & & & & & 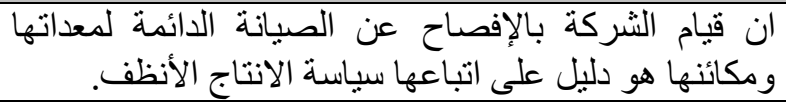 & 11 \\
\hline & & & & & 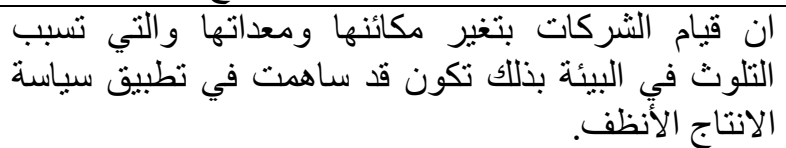 & ir \\
\hline & & & & & للمعدات و المكائن قد يسهم في التباع سياسة الانتاج التصيم الأنظف. & Ir \\
\hline & & & & & 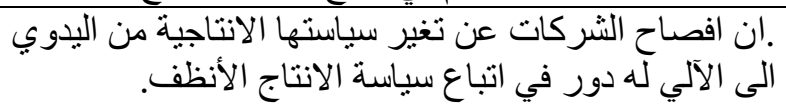 & $1 \varepsilon$ \\
\hline & & & & & 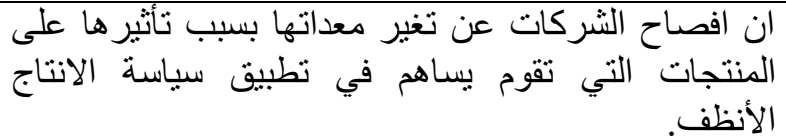 & 10 \\
\hline \multicolumn{7}{|c|}{ المحور الرابع: الافصاح عن الأنشطة البيئية الخاصة بتغير في تصميم المنتج ويتطلب استبدالها بالإنتاج الأنظف } \\
\hline \multirow[t]{6}{*}{ لا بشدة } & ا ت أتفق & محايد & أتقق & 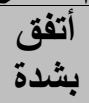 & الأسئلة & \\
\hline & & & & & لجوء الثركات اللى تقديم منتجات الانظف صديقة للبيئة لله انعكاس & 17 \\
\hline & & & & & 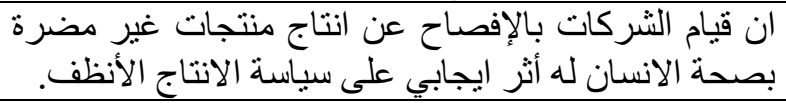 & IV \\
\hline & & & & & 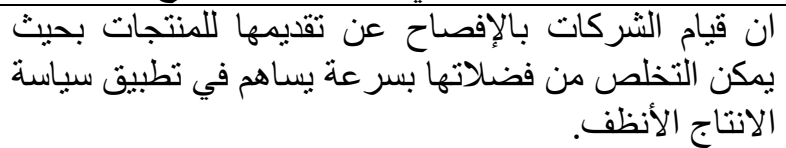 & 11 \\
\hline & & & & & 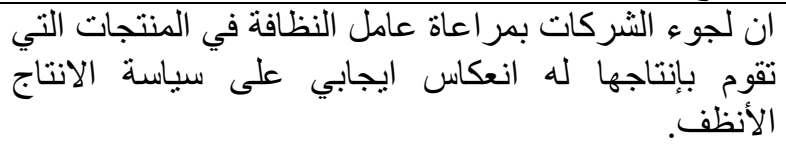 & 19 \\
\hline & & & & & 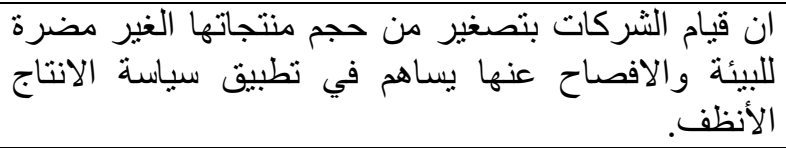 & r. \\
\hline \multicolumn{7}{|c|}{ الأنظفو الخامس: الافصاح عن الأنشطة البيئة الخاصة بادارة النفايات والمخلفات ويتطلب استبالها بالإنتاج } \\
\hline \multirow[t]{6}{*}{ لالأنق } & 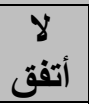 & محايد & أتقق & بشدة - أنق & الأسئلة & \\
\hline & & & & & 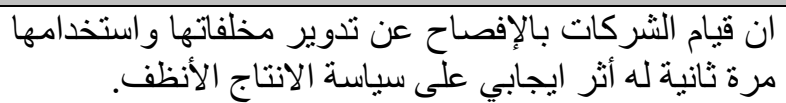 & YI \\
\hline & & & & & انعكاس ايجابي على سياسة الانتاج الأنظف. طن طمر مخلفاتها له & rr \\
\hline & & & & & 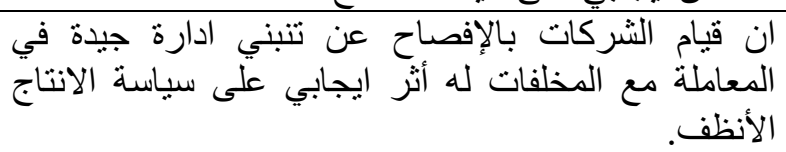 & r \\
\hline & & & & & الانظيث لا نؤثر الثركات عن قيامها بالتخلص من البيئة تناهم في تطبيق سياسة الانتاج & $r \varepsilon$ \\
\hline & & & & & ايجابي عيام الثركات سياسة الانتلاج الأنظففات الى اقل حد ممكن له أثر & ro \\
\hline
\end{tabular}

